\title{
Gaming strategies within a green supply chain considering consumers' concern about the greenness and conformance quality of products
}

yongxi yi ( $\square$ yyx19999@126.com )

University of south china https://orcid.org/0000-0002-2479-4488

Min Yang

University of South China

Chunyan Fu

University of South China

Yuqiong Li

University of South China

\section{Research Article}

Keywords: Green product supply chain, Consumer preferences, Environmental responsibility, Conformance quality

Posted Date: February 15th, 2022

DOI: https://doi.org/10.21203/rs.3.rs-1305019/v1

License: (c) (i) This work is licensed under a Creative Commons Attribution 4.0 International License. Read Full License 
Gaming strategies within a green supply chain considering consumers' concern about the greenness and conformance quality of products

Yongxi Yi*; Min Yang; Chunyan Fu; Yuqiong Li

(School of Economics Management and Law, University of South China)

Corresponding author: Yongxi Yi. Email: yyx19999@126.com

Abstract: Improving the greenness and conformance quality of a product is two fundamental and intertwined considerations in today's supply chain decision-making. However, the related literature rarely considers conformance quality improvement of products in green supply chain management. This paper incorporates both into a framework to analyze the optimal strategies of a manufacturer responsible for conformance quality of product and greenness improvement and a retailer responsible for product marketing in a supply chain under four contracts: full cooperation, price-only contract, two-part tariff, and marketing cost-sharing. The analysis shows that full cooperation and two-part tariffs lead to the same and highest product quality, greenness, overall profit, and social welfare, but full cooperation is difficult to achieve in the supply chain. For the profit-maximizing manufacturer and retailer, the manufacturer most prefers two-part tariff contracts while the retailer prefers marketing cost-sharing because both achieve the highest profit in the preferred contract. Under the price-only contract, conformance quality of product and greenness are lowest, and profit levels for manufacturers and retailers are lowest. In all four cases, increased environment and quality awareness contribute to improved product greenness and conformance quality, leading to higher profits for the manufacturer and retailer and higher social welfare.

Keywords: Green product supply chain; Consumer preferences; Environmental responsibility; Conformance quality

\section{Introduction}

With the emergence of serious environmental problems such as global warming, ozone layer depletion, acid rain, energy shortage, declining forest resources, human beings have become more and more aware of the protection of the ecological environment, and the concept of green development and sustainable development has gradually gained popularity. Furthermore, the 
impact of supply chain operations on the environment is also getting more and more attention, and it is generally accepted that a green supply chain is the future developing direction (Liu, 2019). Therefore, many enterprises are undergoing green transformation and upgrading driven by governments, society, and the public.

Environmental regulation is the main external driver for the green transformation of supply chains. Many countries and regions have enacted laws and regulations to promote sustainable supply chain management systems. This management system focuses on environmental issues, circular economy, and sustainable supply chain development through green product design, green manufacturing, green recycling, reverse logistics (Ji et al., 2017; Li et al., 2021; Chen and Hu, 2018). Furthermore, many empirical studies have revealed that government environmental regulations significantly impact the green development of supply chains (Wang et al., 2020).

Meanwhile, consumers' green awareness is an essential market driver that promotes sustainable and green supply chain development. According to a survey implemented by Accenture, more than $80 \%$ of respondents consider the greenness of a product when making a purchase (Hong and Guo, 2019). Also, a survey report from the Carbon Trust implies that about $20 \%$ of customers prefer to buy green products, even if they are more expensive than regular products ( $\mathrm{Li}$ et al., 2021). In addition to consumer concerns about environmental conditions, factors driving increased consumer awareness include government and environmental organizations advocacy and green marketing by the supply chain (Ma et al., 2017). The supply chain needs to develop increasingly green products to demonstrate its social responsibility due to the pressure from governments and the public. Enhanced marketing of green products then becomes an essential means of profiting from green products. Therefore, retailers often invest in green marketing alone or partnership with manufacturers, such as flat-rate marketing and advertising. For example, Procter \& Gamble has partnered with Wal-Mart, one of the world's largest retailers, in a series of green product marketing efforts (Li et al., 2021). As a result, more and more consumers prefer to buy green products that are non-polluting and environmentally friendly, resulting in more competitive green products than traditional products. Therefore, a supply chain has to introduce green products preferred by consumers to achieve growth continuously.

In addition to ensuring the green attributes of the products, the improvement of conformance 
quality of products, which refers to conformance and defect avoidance in the implementation of a function to achieve a target level, is a critical factor in the greening of the supply chain. Many industries are now using improved conformance quality as a potent competitive tool to meet consumer expectations (He et al., 2016; Lambertini, 2018). Failure to meet this expectation of consumers may lead to a reduction in sales of related products and the loss of goodwill of the company, which in turn, has negative consequences for the manufacturers' ability to sustain its position in the market (Hendricks and Singhal 2004). For example, in 2011, the Ford brand dropped ten spots in Consumer Reports' annual automotive reliability survey due to deteriorating conformance quality. In order to change this situation, "quality" became Ford's "job number one" (Durbin and Krisher, 2011). As a result, Ford moved up to fourth place in the 2012 annual rankings by focusing on quality, beating out BMW, Hyundai, and even Toyota. It is Ford's best position in the report's 31-year history (Chakraborty, 2019). This case of Ford shows that without the improvement of conformance quality of products only to improve the product's greenness, the product provided by the supply chain still can not be favored by consumers, and this development model is inevitably unsustainable.

However, existing literature on green supply chains has focused on improving product greenness but rarely considered improving the conformance quality of products. Therefore, this paper incorporates both considerations for supply chain decisions into the same analytical framework, examines the equilibrium results of the game between manufacturers and retailers under different strategies such as full cooperation, price-only contracts, price discrimination, and marketing cost-sharing, and draws management insightful conclusions by comparing the results between the four strategies.

The remainder of the article is as follows. Section 2 reviews the relevant research. The materials and methods grow up in Section 3, including the basic assumptions and the game's equilibrium results under the four cases. Section 4 shows the comparative analysis of the results. Finally, Section 5 summarizes the paper.

\section{Literature review}

This study is closely related to two research streams: green management in the supply chain and conformance quality of products management in the supply chain. In the following sections, 
we will review the research related to each research stream. Moreover, highlight the differences between this study and the existing literature.

The first research stream closely related to our paper is operational decision-making in green and sustainable supply chain management, which mainly includes sustainable product design, by-products generated during product use, and reverse logistics (Gaur et al., 2017; Yi et al., 2021). An extensive literature has emerged in these areas, and our research focuses on sustainable product design.

Green and sustainable product design requires appropriately positioning the product's function, assessing the environmental impact in product production, consumption, and even post-consumption scenarios, and weighing the economic benefits against the environmental costs (Gouda et al., 2016; Hong et al., 2017). Chen (2001) studies the environmental impact of green product development and concludes that strict environmental standards are unnecessary for environmental improvement. Gouda (2016) proposes a composite environmental regulation to regulate automakers and finds that automakers could achieve economies of scale while delivering environmental benefits under the regulation. Hong et al. (2018) analyze the supply chain configuration of a green product family issue. The objective is to minimize the overall cost of the supply chain by optimizing service time and option selection decisions. Pakseresht et al. (2020) analyze how to optimize the development of the green products family in the supply chain by making the best choices for suppliers, manufacturers, assembly plants, distribution centers, and retailers. By comparing the two models of manufacturer-led and retailer-led green product development, Li et al. (2021) find that the greenness of the products and the profitability of the leaders are higher under the former model. Assuming that the manufacturer grants a credit period to the retailer or gives the retailer a discount on the sales price, Ghoshet et al. (2021) develop a model of coordination between the manufacturer and the retailer regarding the reality of green products and analyze the payments made by each party under each model. Yi et al. (2021a,b) analyze the impact of post-consumer product regulation policies on the life-cycle greenness of products provided by the supply chain under Extended Producer Responsibility (EPR).

The second research stream relevant to our paper is the conformance quality of products management in the supply chain. Improving product quality is the most effective means for supply chains to achieve a competitive advantage, and it has received close attention from the academic 
community (Chen et al., 2017; Lambertini, 2018). Much research has focused on the quality management of supply chain collaboration (Reyniers and Tapiero,1995; Lee et al., 2013; El and Kogan, 2013; Lambertini, 2018; Chakraborty et al.2019). For example, El and Kogan (2013) believe that even though revenue-sharing contract contracts increase the commitment of suppliers to improve quality, such contracts do not entirely solve the coordination problem. While Chakraborty et al. (2019) argue that the cost-sharing model is an effective way of cooperation, and it has higher product quality and profit levels than price contracts. Lambertini (2018) analyzes the coordination of two firms belonging to the same supply chain that make joint R\&D investments to improve product quality and finds that vertically integrated supply chains can effectively coordinate using a two-part tariff contract. Baiman et al. (2000) analyzed the relationship between product quality, cost of quality, and contractable information among supply chain participants. Gray (2015) investigates the conformance quality benefits of combining production and R\&D activities and finds that the closer the location of production and R\&D activities is, the higher the conformance quality of products. Krishna et al. (2000) believe that improved conformance quality of software products has a positive impact on product-lifecycle productivity and good staff quality, deployment of product development resources, and improvement of the production process can guarantee improvement conformance quality of software products. Nandakumar et al. (1993) develop a dynamic programming model to evaluate the cost of conformance quality of products and show that it may not be optimal for quality improvement efforts to target products with the highest defective levels, the highest direct costs, or consume the maximum capital resources. Thirumalai (2011) finds that the conformance quality of medical products directly affects the probability of product recall, consumers' demand for the company's products, and even the company's reputation.

Although the existing literature has extensively studied green and product quality management in supply chains, these two issues rarely enter the same analytical framework, with a slight exception. Chen (2001) develops a quality-based model to investigate green product development where the product quality and environmental consequences simultaneously enter the producer's decision function. Inspired by Chen (2001), in this paper, we extend Chen (2001)'s precious work with the following four distinct differences:

(1) We move decision-makers from a single manufacturer to a supply chain due to the 
development of management science, the strategic interaction between each main body of the supply chain is becoming more and more common in today's product supply side (Liu 2019; Li et al. 2021).

(2) Concerning "product quality" in this paper, we focus on products' "conformance quality". The reasons are as follows: as far as we know, the quality of products can be subdivided into conformance quality, design quality, perceived quality, etc. Although the manufacturer is responsible for improving the quality mentioned above, it can also assign some responsibility to the designer or retailer in the supply chain. The perceived quality, for example, can be improved by retailers' increased marketing efforts, while the improvement of the conformance quality of the product can only be performed by the manufacturer alone. Therefore, to avoid confusion of responsibility, we limit the quality of the product improved by the manufacturer to "conformance quality" in this paper.

(3) An entirely new demand function is developed in which, in addition to product price, product greenness and conformance quality, and marketing efforts jointly and positively affect product demand.

(4) We analyze the best decisions of the manufacturer and retailer and their respective payments and social welfare under four scenarios: full cooperation, wholesale price contract, price discrimination, and marketing cost-sharing, and compare the equilibrium results of the game in the four scenarios to conclude the study.

\section{Materials and Methods}

\subsection{Problem description}

Consider that there is a two-echelon supply chain consisting of a manufacturer and a retailer. The manufacturer is responsible for producing a product of improved conformance quality and green. The retailer advertises and sells it. Consumers prefer good quality and green products. It competes for market share with traditional products that are functionally identical to those in the supply chain that we investigated and already existed in the marketplace.

As the leader in our leader-follower game, the manufacturer first determines the product's conformance quality, degree of greenness, and wholesale price. Then, as the game follower, the retailer assumes advertising effort and the product's retail price. We consider different tour ways 
that the manufacturer and retailer can choose to play in the game: full channel coordination, a price-only contract, a two-part tariff contract, and a marketing cost-sharing contract. Moreover, we indicate them with "c", "d", "tt", and "cs" respectively for notational convenience.

\subsection{Fundamental assumption}

To describe the model more clearly and conveniently, we summarize the symbols and definitions of the variables and parameters used in the model in Table 1 below.

Table 1 Parameters and variables symbol descriptions

\begin{tabular}{|c|c|c|c|}
\hline \multicolumn{2}{|r|}{ Variables } & $S W$ & Social welfare level \\
\hline$q$ & Conformance quality level of the products & $c$ & Marginal cost of product production \\
\hline$e$ & Greenness of the product & & \\
\hline$t$ & Product marketing effort level & & Parameters \\
\hline$D$ & Number of demand for the product & $\alpha$ & $\begin{array}{l}\text { Cost rate of the green technology } \\
\text { development }\end{array}$ \\
\hline$p$ & Market price of products & $\beta$ & $\begin{array}{l}\text { Difficulty factor of product quality } \\
\text { improvement }\end{array}$ \\
\hline$w$ & Wholesale price of products & $\phi$ & Product marketing cost rate \\
\hline$\pi$ & Profit level & $k_{1}$ & $\begin{array}{l}\text { Consumers' greenness preference for the } \\
\text { product }\end{array}$ \\
\hline EI & $\begin{array}{l}\text { The amount of pollution reduction } \\
\text { converted into money }\end{array}$ & $k_{2}$ & $\begin{array}{l}\text { Consumers' greenness preference for the } \\
\text { product }\end{array}$ \\
\hline$C S$ & Consumer surplus & $\varepsilon$ & $\begin{array}{l}\text { Conversion factor for converting } \\
\text { pollution emission reductions to money }\end{array}$ \\
\hline
\end{tabular}

To meet consumer demand and gain an advantage in the competitive marketplace, the manufacturer and retailer in the supply chain perform their roles.

On the one hand, the manufacturer is responsible for improving the conformance quality $q(0<q<1)$ and greenness $e(0<e<1)$ of the product. Consistent with related studies such as Lambertini (2018) and Chakraborty et al. (2019) and Chen (2001), assume that to improve the product conformance quality of the product $q$ costs the manufacturer an investment $\operatorname{cost} \beta q^{2}$.

195 It is a convex increasing function in line with the basic view of microeconomics, where the 196 constant $\beta$ represents the difficulty factor of product quality improvement. Product greenness $e$ indicates the percentage of emissions saved relative to conventional products. Its 
improvement depends on the development of green technologies of the manufacturer. Following Hong et al. (2019) and Li et al. (2021), we assume that the investment cost of the development of green technologies is $\alpha e^{2}$ for obtaining the greenness $e$. Where $\alpha$ is the cost rate of the green technology development.

On the other hand, the retailer is responsible for marketing the product. It promotes product sales through advertising efforts $t$. Usually, higher advertising efforts require more advertising costs and will result in more product sales. In agreement with Atasu et al. (2009) and Hong et al. (2019), we assume the product marketing cost rate of the retailer is $\phi$ and it suffer a convex and increasing advertising cost $\phi t^{2}$.

Now, let us investigate the consumption function. Firstly, as with recent research on green supply chains, consumers are environmentally conscious. Therefore, they are willing to pay higher prices for greener products or more quantity in demand at the same price (same below). Secondly, according to common perceptions, consumers are more willing to pay when faced with a higher quality product. In particular, Thirumalai et al. (2011)'s empirical research shows that the conformance quality of products positively impacts product demand. This idea is supported by relevant research such as Hendricks (2003). Thirdly, as shown in recent studies such as Hong et al. (2019), Retailers' advertising efforts are a direct factor in increasing consumers' willingness to pay. Fourthly, as demand functions generally, there is an inverse relationship between the quantity demanded and the price, i.e., a higher price leads to a lower quantity demanded. Combining the above four factors, obtain our demand function as follows:

$$
D=1-p+k_{1} e+k_{2} q+t
$$

where $k_{1}$ and $k_{2}$ are consumers' greenness preference and quality preference for the product, respectively. In addition, we unitize the market size and the marginal effect of price and advertising on the quantity demanded as 1 , which is consistent with recent related studies such as Hong et al. (2019).

In the following, We first investigate the form of full channel coordination as a benchmark for comparison. In this form, the manufacturer and retailer in the supply chain can be treated as one profit center from two independent profit centers, and they choose the optimal strategy to 
maximize the profit of the entire consortium.

\subsection{Game equilibrium under full channel coordination (c)}

In the case of full channel coordination, the manufacturer and retailer make decisions from a holistic perspective. The decision-making order under full channel coordination is shown in Fig.1.

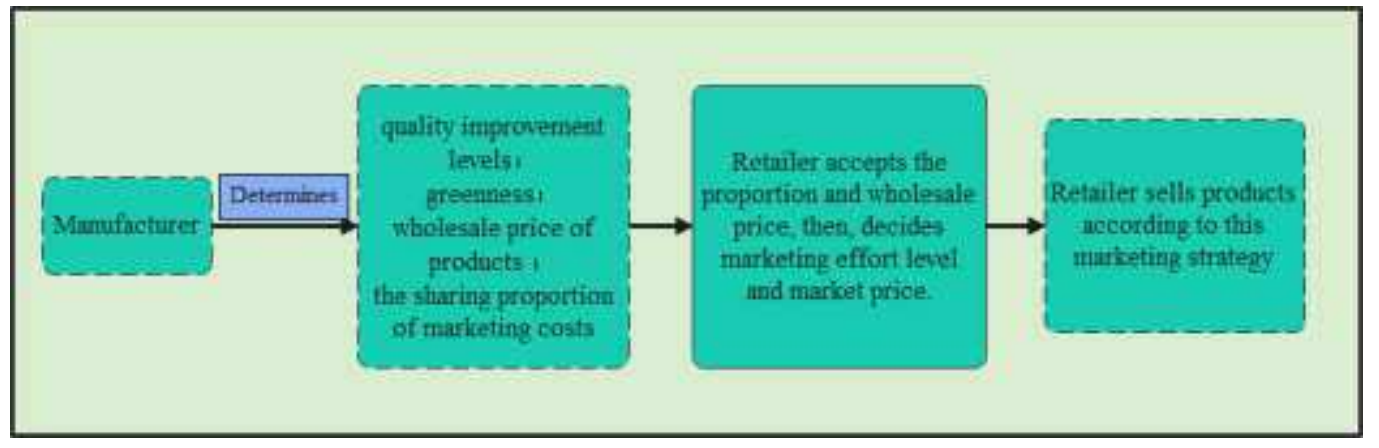

Fig. 1. Decision-making order under full channel coordination

Therefore, we can give their joint objective function as the following equation:

$$
\pi_{c}\left(p_{c}, t_{c}, e_{c}, q_{c}\right)=\left(p_{c}-c\right)\left(1-p_{c}+k_{1} e_{c}+k_{2} q_{c}+t_{c}\right)-\alpha e_{c}^{2}-\beta q_{c}^{2}-\phi t_{c}^{2}
$$

According to the first-order and second-order conditions of Eq. (2), one can get the optimal strategies under the full channel coordination as described in Theorem 1:

Theorem 1. Under the full channel coordination, the optimal equilibrium strategies for the manufacturer and the retailer are:

$$
p_{c}^{*}=c+\frac{2 \alpha \beta \phi(1-c)}{\alpha \beta(4 \phi-1)-\phi\left(\beta k_{1}^{2}+\alpha k_{2}^{2}\right)}, t_{c}^{*}=\frac{\alpha \beta(1-c)}{\alpha \beta(4 \phi-1)-\phi\left(\beta k_{1}^{2}+\alpha k_{2}^{2}\right)}
$$

$$
e_{c}^{*}=\frac{\beta \phi k_{1}(1-c)}{\alpha \beta(4 \phi-1)-\phi\left(\beta k_{1}^{2}+\alpha k_{2}^{2}\right)}, q_{c}^{*}=\frac{\alpha \phi k_{2}(1-c)}{\alpha \beta(4 \phi-1)-\phi\left(\beta k_{1}^{2}+\alpha k_{2}^{2}\right)} .
$$

We put the proof of Theorem 1 in Appendix 1.

Substituting the optimal equilibrium strategies stated in Theorem 1 into Eq. (2), obtain the production and total profit of the supply chain :

$$
D_{c}^{*}=\frac{2 \alpha \beta \phi(1-c)}{\alpha \beta(4 \phi-1)-\phi\left(\beta k_{1}^{2}+\alpha k_{2}^{2}\right)} ; \pi_{c}^{*}=\frac{\alpha \beta \phi(1-c)^{2}}{\alpha \beta(4 \phi-1)-\phi\left(\beta k_{1}^{2}+\alpha k_{2}^{2}\right)}
$$

Let us next employ Corollary 1 to investigate the effect of specific system parameters on the optimal decisions of the manufacturer and retailer.

Corollary 1. The optimal decisions under full channel coordination have the following properties: 
(1) $\frac{\partial p_{c}^{*}}{\partial \alpha}<0, \frac{\partial t_{c}^{*}}{\partial \alpha}<0, \frac{\partial e_{c}^{*}}{\partial \alpha}<0, \frac{\partial q_{c}^{*}}{\partial \alpha}<0, \frac{\partial \pi_{c}^{*}}{\partial \alpha}<0$. (2) $\frac{\partial p_{c}^{*}}{\partial \beta}<0, \frac{\partial t_{c}^{*}}{\partial \beta}<0, \frac{\partial e_{c}^{*}}{\partial \beta}<0$,

$\frac{\partial q_{c}^{*}}{\partial \beta}<0, \frac{\partial \pi_{c}^{*}}{\partial \beta}<0$. (3) $\frac{\partial p_{c}^{*}}{\partial \phi}<0, \frac{\partial t_{c}^{*}}{\partial \phi}<0, \frac{\partial e_{c}^{*}}{\partial \phi}<0, \frac{\partial q_{c}^{*}}{\partial \phi}<0, \frac{\partial \pi_{c}^{*}}{\partial \phi}<0$. (4) $\frac{\partial p_{c}^{*}}{\partial k_{1}}>0, \frac{\partial t_{c}^{*}}{\partial k_{1}}>0$,

$\frac{\partial e_{c}^{*}}{\partial k_{1}}>0, \frac{\partial q_{c}^{*}}{\partial k_{1}}>0, \frac{\partial \pi_{c}^{*}}{\partial k_{1}}>0$. (5) $\frac{\partial p_{c}^{*}}{\partial k_{2}}>0, \frac{\partial t_{c}^{*}}{\partial k_{2}}>0, \frac{\partial e_{c}^{*}}{\partial k_{2}}>0, \frac{\partial q_{c}^{*}}{\partial k_{2}}>0, \frac{\partial \pi_{c}^{*}}{\partial k_{2}}>0$.

The higher cost of green technology development decreases optimal greenness investment, decreasing consumer demand and product prices. We also find a cascade of other responses by the consortium to higher green technology development costs: optimal marketing efforts, conformance quality improvement efforts, and even overall profits decline. From (2)and (3), We can see that the increase in marketing effort cost and conformance quality improvement cost has the same effect on each variable as the increase in product greenness improvement cost. This phenomenon reflects that conformance quality improvement, greenness improvement, and product marketing have a complementary relationship in the profit consortium of the supply chain. Improving one will improve the other two and improve demand, raise demand prices, and increase profits. We find from (4) and (5) that the increase in consumer preference for product greenness or quality motivates the profit consortium to invest in conformance quality of the product and greenness and enhance product marketing, resulting in an overall increase in profits.

The overall profit level of the supply chain may be substantial under full channel coordination. However, according to our analysis in Appendix 1, the optimal prices and marketing efforts must obey the following relationships to achieve full cooperation:

$$
t^{*}=\frac{p^{*}-c}{2 \phi}
$$

If Equation (3) is valid, then the wholesale price equals the manufacturer's marginal cost, i.e., $w^{*}=c$. It makes the manufacturer cannot improve product quality and product greenness. Otherwise, it will incur a loss. Thus, the mode of the entire channel coordination is contrary to the assumptions of this paper. In other words, full channel coordination is not feasible in our model. Therefore, we next examine other feasible game strategies for them, including single-price strategy, price discrimination strategy, and marketing cost-sharing strategy. 


\subsection{Game equilibrium under single-price contract (d)}

We apply the inverse induction method to investigate the supply chain decision under a price-only contract in a Stackelberg game framework. The manufacturer, as the leader, offers the product to the retailer at its optimal wholesale price. The retailer acts as a follower, buys the product from the manufacturer at the wholesale price determined by the manufacturer, and sells the product to the consumer at its optimal retail price. We show the decision-making order under a price-only contract in Fig.2.

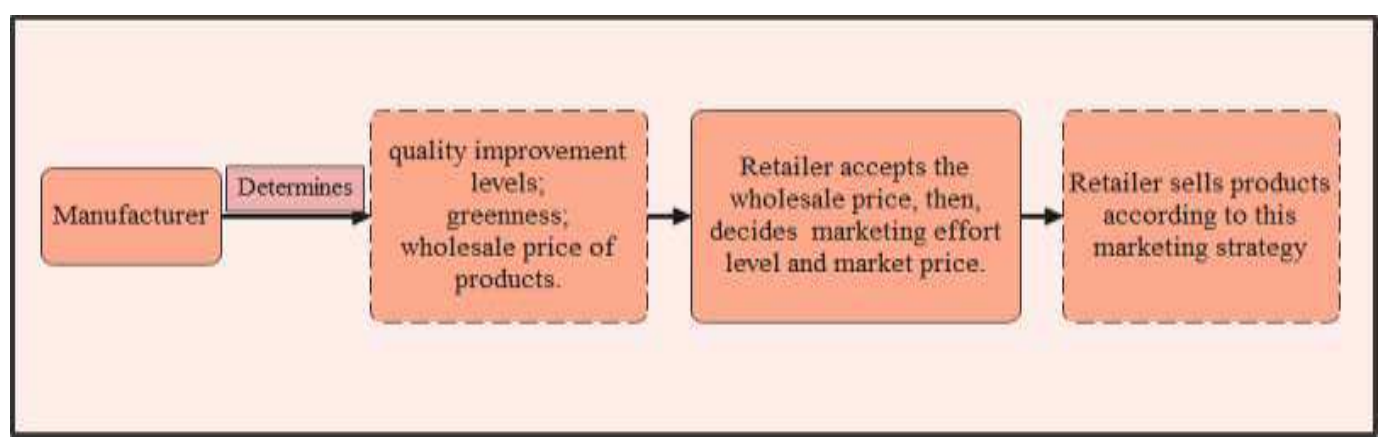

Fig.2 Decision-making order under a price-only contract

We first analyze the optimal decision of the retailer who acts as the follower in the game. In response to the manufacturer's decisions of $e_{d}, w_{d}$ and $q_{d}$, the retailer determines his optimal advertising effort $t_{d}$ and retail price $p_{d}$. We phrase the retailer's issue as follows.

$$
\pi_{d}^{r}\left(p_{d}, t_{d}\right)=\left(p_{d}-w_{d}\right)\left(1-p_{d}+k_{1} e_{d}+k_{2} q_{d}+t_{d}\right)-\phi t_{d}^{2}
$$

From the first-order and second-order conditions of Eq.(5), we find that $\pi_{d}^{r}\left(p_{d}, t_{d}\right)$ is jointly concave in $\left(p_{d}, w_{d}\right)$, and the unique optimal decision pair $\left(p_{d}^{*}, t_{d}^{*}\right)$ in reaction to $e_{d}$, $w_{d}$ and $q_{d}$ can be given as:

$$
\begin{aligned}
& p_{d}^{*}\left(w_{d}, \quad e_{d}, \quad q_{d}\right)=\frac{2 \phi\left(1+k_{1} e_{d}+k_{2} q_{d}+w_{d}\right)-w_{d}}{4 \phi-1} \\
& t_{d}^{*}\left(w_{d}, \quad e_{d}, \quad q_{d}\right)=\frac{1+k_{1} e_{d}+k_{2} q_{d}-w_{d}}{4 \phi-1}
\end{aligned}
$$

Next, consider the problem of the manufacturer who acts as the leader in the game. Under the marginal production cost $c$, the manufacturer has the following profit functions:

$$
\pi_{d}^{m}\left(w_{d}, e_{d}, q_{d}\right)=\left(w_{d}-c\right)\left(1-p_{d}+k_{1} e_{d}+k_{2} q_{d}+t_{d}\right)-\alpha e_{d}^{2}-\beta q_{d}^{2}
$$



conditions of Eq.(7), can obtain the manufacturer's game equilibrium strategies. Combining Eqs. (5) and (6), we conclude the following theorem 2.

Theorem 2. Under the price-only contract, the Stackelberg equilibrium of the supply chain can be given as:

$$
p_{d}^{*}=\frac{2 \alpha \beta \phi(3+c)-\alpha \beta(1+c)-c \phi\left(\beta k_{1}^{2}+\alpha k_{2}^{2}\right)}{2 \alpha \beta(4 \phi-1)-\phi\left(\beta k_{1}^{2}+\alpha k_{2}^{2}\right)}, \quad t_{d}^{*}=\frac{\alpha \beta(1-c)}{2 \alpha \beta(4 \phi-1)-\phi\left(\beta k_{1}^{2}+\alpha k_{2}^{2}\right)}
$$

$$
w_{d}^{*}=\frac{\alpha \beta(1+c)(4 \phi-1)-c \phi\left(\beta k_{1}^{2}+\alpha k_{2}^{2}\right)}{2 \alpha \beta(4 \phi-1)-\phi\left(\beta k_{1}^{2}+\alpha k_{2}^{2}\right)}, \quad e_{d}^{*}=\frac{\phi \beta k_{1}(1-c)}{2 \alpha \beta(4 \phi-1)-\phi\left(\beta k_{1}^{2}+\alpha k_{2}^{2}\right)},
$$

$$
q_{d}^{*}=\frac{\phi \alpha k_{2}(1-c)}{2 \alpha \beta(4 \phi-1)-\phi\left(\beta k_{1}^{2}+\alpha k_{2}^{2}\right)} \text {. }
$$

Substituting the game equilibrium results into Eq. (4) and (7), receive the production and the contract:

$$
D_{d}^{*}=\frac{2 \alpha \beta \phi(1-c)}{2 \alpha \beta(4 \phi-1)-\phi\left(\beta k_{1}^{2}+\alpha k_{2}^{2}\right)} ; \quad \pi_{d}^{r^{*}}=\frac{\alpha^{2} \beta^{2} \phi(1-c)^{2}(4 \phi-1)}{\left[2 \alpha \beta(4 \phi-1)-\phi\left(\beta k_{1}^{2}+\alpha k_{2}^{2}\right)\right]^{2}}
$$

$$
\pi_{d}^{m^{*}}=\frac{\alpha \beta \phi(1-c)^{2}}{\left[2 \alpha \beta(4 \phi-1)-\phi\left(\beta k_{1}^{2}+\alpha k_{2}^{2}\right)\right]}
$$

$$
\pi_{d}^{*}=\pi_{d}^{r^{*}}+\pi_{d}^{m^{*}}=\frac{\alpha \beta \phi(1-c)^{2}\left[3 \alpha \beta(4 \phi-1)-\phi\left(\beta k_{1}^{2}+\alpha k_{2}^{2}\right)\right]}{\left[2 \alpha \beta(4 \phi-1)-\phi\left(\beta k_{1}^{2}+\alpha k_{2}^{2}\right)\right]^{2}}
$$

It is time to employ Corollaries 2 to investigate the effects of specific system parameters on the optimal decisions of the manufacturer and retailer under a price-only contract.

Corollary 2. The optimal decisions under a price-only contract have the following properties:

$$
\text { (1) } \frac{\partial p_{d}^{*}}{\partial \alpha}<0, \frac{\partial t_{d}^{*}}{\partial \alpha}<0, \frac{\partial w_{d}^{*}}{\partial \alpha}<0, \frac{\partial e_{d}^{*}}{\partial \alpha}<0, \frac{\partial q_{d}^{*}}{\partial \alpha}<0, \frac{\partial \pi_{c}^{*}}{\partial \alpha}<0 \text {.(2) } \frac{\partial p_{d}^{*}}{\partial \beta}<0, \frac{\partial t_{d}^{*}}{\partial \beta}<0 \text {, }
$$

$$
\frac{\partial w_{d}^{*}}{\partial \beta}<0, \frac{\partial e_{d}^{*}}{\partial \beta}<0, \frac{\partial q_{d}^{*}}{\partial \beta}<0, \frac{\partial \pi_{d}^{r^{*}}}{\partial \beta}<0 \text {.(3) } \frac{\partial p_{d}^{*}}{\partial \phi}<0, \frac{\partial t_{d}^{*}}{\partial \phi}<0, \frac{\partial w_{d}^{*}}{\partial \phi}<0, \frac{\partial e_{d}^{*}}{\partial \phi}<0, \frac{\partial q_{d}^{*}}{\partial \phi}<0,
$$

$$
\frac{\partial \pi_{d}^{r^{*}}}{\partial \phi}<0 \quad \text {.(4) } \frac{\partial p_{d}^{*}}{\partial k_{1}}>0, \frac{\partial t_{d}^{*}}{\partial k_{1}}>0, \frac{\partial w_{d}^{*}}{\partial k_{1}}>0, \frac{\partial e_{d}^{*}}{\partial k_{1}}>0, \frac{\partial q_{d}^{*}}{\partial k_{1}}>0, \frac{\partial \pi_{d}^{r^{*}}}{\partial k_{1}}>0
$$

(5) $\frac{\partial p_{d}^{*}}{\partial k_{2}}>0, \frac{\partial t_{d}^{*}}{\partial k_{2}}>0, \frac{\partial w_{d}^{*}}{\partial k_{2}}>0, \frac{\partial e_{d}^{*}}{\partial k_{2}}>0, \frac{\partial q_{d}^{*}}{\partial k_{2}}>0, \frac{\partial \pi_{d}^{r^{*}}}{\partial k_{2}}>0$. 
The proof of Theorem 2 and Corollary 2can be found in Appendix 2 .

\section{8}

Corollary 2 shows that even when manufacturers and retailers make independent decisions based on their profit maximization, the impact of the optimal decision of the system parameters is consistent with the results in combined manufacturer and retailer decisions.

Having completed the game analysis under the price contract, let us next investigate the marketing cost-sharing model.

\subsection{Game equilibrium under a two-part tariff contract (tt)}

The two-part tariff system is a typical price discrimination strategy used by monopolistic players. On the one hand, it enables to convert all consumer surplus into producer surplus. However, on the other hand, it can eliminate the surplus loss caused by monopoly and achieve the Pareto optimal result (Basak et al., 2016). This subsection assumes that the manufacturer uses the two-part tariff system, i.e., a price discrimination strategy, for the retailer. The price charged by the manufacturer to the retailer consists of two parts: the wholesale price $w_{t t}$ and a fixed fee $T$. The decision-making order under a two-part tariff contract is described in Fig.3.

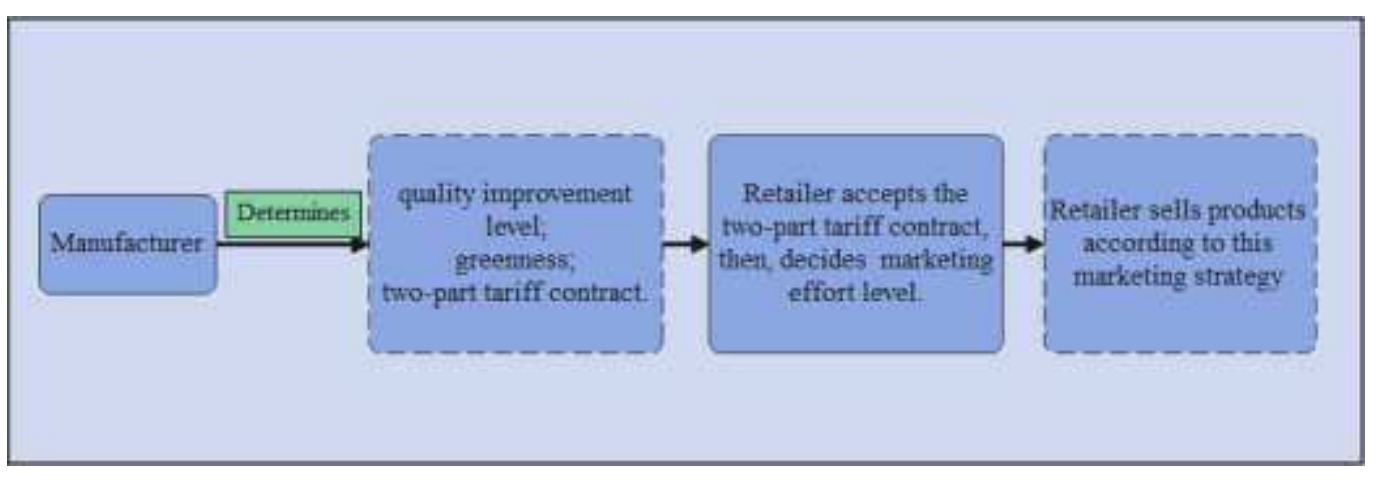

Fig.3 Decision-making order under a two-part tariff contract

Therefore, the retailer's objective function converts into the following form:

$$
\pi_{t t}^{r}\left(p_{t t}, t_{t t}\right)=\left(p_{t t}-w_{t t}\right)\left(1-p_{t t}+k_{1} e_{t t}+k_{2} q_{t t}+t_{t t}\right)-\phi t_{t t}^{2}-T
$$

Meanwhile, the manufacturer's objective function can be expressed by the following equation:

$$
\begin{aligned}
& \pi_{t t}^{m}\left(w_{t t}, T, e_{t t}, q_{t t}\right)=\left(w_{t t}-c\right)\left(1-p_{t t}+k_{1} e_{t t}+k_{2} q_{t t}+t_{t t}\right)-\alpha e_{t t}^{2}-\beta q_{t t}^{2}+T \\
& \text { s.t. } \quad\left(p_{t t}^{*}-w_{t t}\right)\left(1-p_{t t}^{*}+k_{1} e_{t t}+k_{2} q_{t t}+t_{t t}^{*}\right)-\phi t_{t t}^{* 2}-T \geq \pi_{d}^{r^{*}}
\end{aligned}
$$

Since the manufacturer is the leader in the Stackelberg game, it can take full advantage of its first-mover advantage to maximize its profits. I.e., it can increase its fixed-fee charges until the 
retailer is just ready to accept the contract. Therefore, the following equation holds.

$$
\left(p_{t t}^{*}-w_{t t}\right)\left(1-p_{t t}^{*}+k_{1} e_{t t}+k_{2} q_{t t}+t_{t t}^{*}\right)-\phi t_{t t}^{* 2}-T=\pi_{d}^{r^{*}}
$$

Thereby, the manufacturer's objective function converts into:

$$
\pi_{t t}^{m}\left(w_{t t}, e_{t t}, q_{t t}\right)=\left(p_{t t}^{*}-c\right)\left(1-p_{t t}^{*}+k_{1} e_{t t}+k_{2} q_{t t}+t_{t t}^{*}\right)-\alpha e_{t t}^{2}-\beta q_{t t}^{2}-\phi t_{t t}^{* 2}
$$

Applying the first-order and second-order conditions of Eqs. (9), (10), and (11) in the framework of the Stackelberg game, we obtain the unique optimal strategy for the manufacturer and the retailer stated in Theorem 3:

Theorem 3. Under a two-part tariff contract model, the Stackelberg game between the manufacturer and the retailer reaches the following equilibrium results:

$$
\begin{aligned}
& w_{t t}^{*}=c, e_{t t}^{*}=\frac{\phi \beta k_{1}(1-c)}{\alpha \beta(4 \phi-1)-\phi\left(\beta k_{1}^{2}+\alpha k_{2}^{2}\right)}, q_{t t}^{*}=\frac{\phi \alpha k_{2}(1-c)}{\alpha \beta(4 \phi-1)-\phi\left(\beta k_{1}^{2}+\alpha k_{2}^{2}\right)}, \\
& p_{t t}^{*}=c+\frac{2 \alpha \beta \phi(1-c)}{\alpha \beta(4 \phi-1)-\phi\left(\beta k_{1}^{2}+\alpha k_{2}^{2}\right)}, t_{t t}^{*}=\frac{\alpha \beta(1-c)}{\alpha \beta(4 \phi-1)-\phi\left(\beta k_{1}^{2}+\alpha k_{2}^{2}\right)}, \\
& T=\frac{\phi(\alpha \beta(1-c))^{2}(4 \phi-1)}{\left[\alpha \beta(4 \phi-1)-\phi\left(\beta k_{1}^{2}+\alpha k_{2}^{2}\right)\right]^{2}}-\frac{\phi(\alpha \beta(1-c))^{2}(4 \phi-1)}{\left[2 \alpha \beta(4 \phi-1)-\phi\left(\beta k_{1}^{2}+\alpha k_{2}^{2}\right)\right]^{2}} .
\end{aligned}
$$

The proof of Theorem 3 can be found in Appendix 3.

Substituting the game equilibrium results given in Theorem 3 into Eqs. (9) and (11), get the production and the total profit of the manufacturer, the retailer, and the entire supply chain under the two-part tariff contract:

$$
\begin{aligned}
& D_{t t}^{*}=\frac{2 \alpha \beta \phi(1-c)}{\alpha \beta(4 \phi-1)-\phi\left(\beta k_{1}^{2}+\alpha k_{2}^{2}\right)} ; \pi_{t t}^{r^{* *}}=\pi_{d}^{r^{*}}=\frac{\phi(\alpha \beta(1-c))^{2}(4 \phi-1)}{\left[2 \alpha \beta(4 \phi-1)-\phi\left(\beta k_{1}^{2}+\alpha k_{2}^{2}\right)\right]^{2}} \\
& \pi_{t t}^{m^{*}}=\frac{\alpha \beta \phi(1-c)^{2}}{\left[\alpha \beta(4 \phi-1)-\phi\left(\beta k_{1}^{2}+\alpha k_{2}^{2}\right)\right]}-\frac{\phi(\alpha \beta(1-c))^{2}(4 \phi-1)}{\left[2 \alpha \beta(4 \phi-1)-\phi\left(\beta k_{1}^{2}+\alpha k_{2}^{2}\right)\right]^{2}} \\
& \pi_{t t}^{*}=\pi_{t t}^{r^{*}}+\pi_{t t}^{m^{*}}=\frac{\alpha \beta \phi(1-c)^{2}}{\left[\alpha \beta(4 \phi-1)-\phi\left(\beta k_{1}^{2}+\alpha k_{2}^{2}\right)\right]}
\end{aligned}
$$

Next, we investigate the decisions of the manufacturer and the retailer in a marketing cost-sharing scenario.

\subsection{Game equilibrium under marketing cost-sharing (cs)}

Under the price-only contract and the two-part tariff contract, either the manufacturer or the retailer chooses strategies to maximize its profits, ignoring the cooperation in the supply chain. This subsection investigates a limited form of collaboration between the manufacturer and the retailer in the supply chain, namely the sharing of marketing costs. 
Stackelberg game, takes the lead in determining the percentage of cost-sharing for advertising efforts. Then, the retailer, i.e., the followers of the Stackelberg game, determines the amount of advertising effort and the product's price under the given cost-sharing ratio. As one can see, in this model, the marketing costs affect the profitability of both parties. Thus, depart from the price-only contract and the two-part tariff contract, the marketing cost-sharing model, requires the cooperation of both parties. However, this cooperation is only on one aspect of marketing cost-sharing, and it is a limited cooperation model for manufacturers and retailers. The following

Fig.4 shows the decision-making order under marketing cost-sharing.

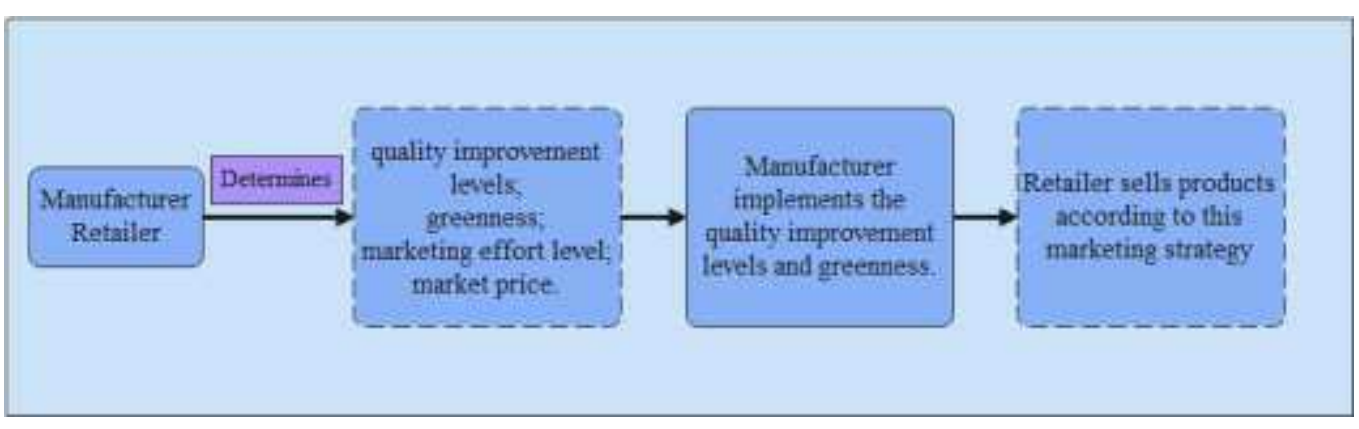

Fig.4 Decision-making order under marketing cost-sharing

Assume that the proportion of marketing costs that the manufacturer is willing to share is $\eta$.Then, the proportion of marketing costs borne by the retailer is $(1-\eta)$ and it has the following objective function:

$$
\pi_{c s}^{r}\left(p_{c s}, t_{c s}\right)=\left(p_{c s}-w_{c s}\right)\left(1-p_{c s}+k_{1} e_{c s}+k_{2} q_{c s}+t_{c s}\right)-(1-\eta) \phi t_{c s}^{2}
$$

Meanwhile, the manufacturer's objective function can be given by equation (13).

$$
\pi_{c s}^{m}\left(w_{c s}, e_{c s}, q_{c s}, \eta_{c s}\right)=\left(w_{c s}-c\right)\left(1-p_{c s}+k_{1} e_{c s}+k_{2} q_{c s}+t_{c s}\right)-\alpha e_{c s}^{2}-\beta q_{c s}^{2}-\eta \phi t_{c s}^{2}
$$

Solving equations (12) and (13) according to Stackelberg's model, we obtain the following Theorem 4.

Theorem 4. Under the marketing cost-sharing model, the Stackelberg game between the manufacturer and the retailer reaches the following equilibrium results:

$$
\begin{aligned}
q_{c s}^{*} & =\frac{4 \phi k_{2} \alpha(c-1)}{4 \phi\left(\beta k_{1}^{2}+\alpha k_{2}^{2}\right)-\alpha \beta(32 \phi-9)}, e_{c s}^{*}=\frac{4 \phi k_{1} \beta(c-1)}{4 \phi\left(\beta k_{1}^{2}+\alpha k_{2}^{2}\right)-\alpha \beta(32 \phi-9)}, \\
w_{c s}^{*} & =\frac{4 \phi c\left(\beta k_{1}^{2}+\alpha k_{2}^{2}\right)+\alpha \beta(3+6 c-16 \phi-16 \phi c)}{4 \phi\left(\beta k_{1}^{2}+\alpha k_{2}^{2}\right)-\alpha \beta(32 \phi-9)}, t_{c s}^{*}=\frac{6 \alpha \beta(c-1)}{4 \phi\left(\beta k_{1}^{2}+\alpha k_{2}^{2}\right)-\alpha \beta(32 \phi-9)},
\end{aligned}
$$




$$
p_{c s}^{*}=\frac{4 \phi c\left(\beta k_{1}^{2}+\alpha k_{2}^{2}\right)-2 c \alpha \beta(4 \phi-3)-3 \alpha \beta(8 \phi-1)}{4 \phi\left(\beta k_{1}^{2}+\alpha k_{2}^{2}\right)-\alpha \beta(32 \phi-9)}, \eta_{c s}^{*}=\frac{1}{3}
$$

Please find the proof of Theorem 4 in Appendix 4.

Substituting the game equilibrium results into Eq. (12) and (13), we obtain the production and the total profit of the manufacturer, the retailer, and the entire supply chain under the marketing cost-sharing:

$$
D_{c s}^{*}=\frac{2 \alpha \beta \phi(1-c)}{\alpha \beta(8 \phi-2.25)-\phi\left(\beta k_{1}^{2}+\alpha k_{2}^{2}\right)} ; \pi_{c s}^{r^{*}}=\frac{8 \phi \alpha^{2} \beta^{2}(c-1)^{2}[8 \phi-3]}{\left[4 \phi\left(\beta k_{1}^{2}+\alpha k_{2}^{2}\right)-\alpha \beta(32 \phi-9)\right]^{2}}
$$

$$
\pi_{c s}^{m^{*}}=\frac{4 \phi \alpha \beta(c-1)^{2}}{\left[\alpha \beta(32 \phi-9)-4 \phi\left(\beta k_{1}^{2}+\alpha k_{2}^{2}\right)\right]}
$$

$$
\pi_{c s}^{*}=\pi_{c s}^{r^{*}}+\pi_{c s}^{m^{*}}=\frac{4 \phi \alpha \beta(c-1)^{2}\left[48 \phi \alpha \beta-15 \alpha \beta-4 \phi\left(\beta k_{1}^{2}+\alpha k_{2}^{2}\right)\right]}{\left[4 \phi\left(\beta k_{1}^{2}+\alpha k_{2}^{2}\right)-\alpha \beta(32 \phi-9)\right]^{2}}
$$

\section{Results discussion}

We have investigated the optimal strategies of the manufacturer and retailer under four scenarios: full channel coordination, a price-only contract, a two-part tariff contract, and a marketing cost-sharing contract. This section will provide a comparative analysis of the strategies under these scenarios.

\subsection{Participants' strategies and profits}

Analyzing the game behavior of manufacturers and retailers in the four cases, we propose the following Proposition1.

Proposition1. The greenness of the product, conformance quality of the product, marketing effort, retail price, and market demand in the four cases meet the following relationships:

1) $e_{d}^{*}<e_{c s}^{*}<e_{t t}^{*}=e_{c}^{*}$

2) $q_{d}^{*}<q_{c s}^{*}<q_{t t}^{*}=q_{c}^{*}$

3) $t_{d}^{*}<t_{c s}^{*}<t_{t t}^{*}=t_{c}^{*}$

4) $p_{c}^{*}=p_{t t}^{*}<p_{d}^{*}<p_{c s}^{*}$

5) $D_{d}^{*}<D_{c s}^{*}<D_{t t}^{*}=D_{c}^{*}$

We put the proof of Proposition 1 in Appendix 5.

In the four cases mentioned above, the entire channel coordination eliminates competition 
between the manufacturer and the retailer. The profit consortium they formed can use this advantage to improve product quality and greenness, enhance product marketing, and minimize price to promote demand and producer surplus. Therefore, the highest greenness and product quality, the most outstanding marketing effort, the lowest product price, and the most significant product demand can reach in this case. However, we have shown that full cooperation is impossible to achieve. Therefore, a two-part tariff contract may be an excellent alternative to full channel coordination. As shown in Theorem 1 and Theorem 3, the results under this scheme are identical to the full cooperation, except for the difference in the manufacturer's and retailer's split of total profits. The reason is that under the two-part tariff contract, the manufacturer takes full advantage of its first-mover advantage and replaces the centralized decision-maker in the fully cooperative consortium. The retailer reduces to the role under the arrangement by the manufacturer where it has to accept the manufacturer's proposed solution for decision making. Therefore, the manufacturers who have achieved the status of central decision-makers make a strategic choice from the overall optimality point of view. So that the overall result, in this case, is the same as in the case of full cooperation. On the other hand, in terms of profit distribution, the manufacturer makes full use of its first-mover advantage to maximize its profit, thus leaving the retailer with a profit only equal to its profit under the price-only contract.

A marketing cost-sharing approach is a limited form of cooperation between the manufacturer and the retailer in the supply chain, the manufacturer in this form actively bears part of the retailer's marketing effort to promote product sales, which will lead to an increase in the product sales effort. According to Corollary 1 and Corollary 2, marketing efforts will improve product quality and greenness, lower prices, and lift demand. Therefore, in this model, marketing effort, conformance quality, greenness, and demand are the second-highest, while product price is the second-lowest.

The manufacturer and the retailer compete to maximize their profits under a price-only contract, with the manufacturer responsible for improving product quality and greenness and the retailer responsible for marketing the product. Although marketing efforts also affect the manufacturer's profits, the manufacturer does not invest in it. Likewise, product greenness and quality improvements benefit the retailer while not spending money on them. Therefore, the marketing effort, product greenness, conformance quality, and demand are minimal in this case. 

marketing inputs.

Proposition 2. Instead of causing the retailer to invest less in marketing, the manufacturer's sharing of marketing costs will cause it to invest more in marketing, i,e., $(1-\eta) \phi\left(t_{c s}^{*}\right)^{2}>\phi\left(t_{d}^{*}\right)^{2}$. The proof of Proposition 2 is put in Appendix 6.

One may assume that if the manufacturer shares in the marketing costs, the retailer will take the opportunity to reduce its marketing investment. Proposition 2, however, gives an opposite conclusion. It is because to the extent that an increase in marketing inputs increases consumer demand. Therefore, the retailer drives the manufacturer's investment in marketing to increase demand for the product by increasing its inputs, thus benefiting both the manufacturer and the retailer.

Profitability is a central consideration for manufacturers and retailers when choosing a strategy. Below, we use Proposition 3 to compare the profit situation in four scenarios.

Proposition 3. Among the price-only contract, the two-part tariff contract, and the marketing cost-sharing contract, the profits of the manufacturer and the retailer satisfy the following relationships:

$$
\text { 1) } \pi_{d}^{m^{*}}<\pi_{c s}^{m^{*}}<\pi_{t t}^{m^{*}}
$$

2) $\pi_{d}^{r^{*}}=\pi_{t t}^{r^{*}}<\pi_{c s}^{r^{*}}$

$$
\text { 3) } \pi_{d}^{*}<\pi_{c s}^{*}<\pi_{t t}^{*}=\pi_{c}^{*}
$$

Please see the proof of Proposition 3 in Appendix 7.

Proposition 3 shows that the manufacturer makes the highest profits under a two-part tariff contract. It is because that the manufacture, through the two-part tariff contract, on the one hand, maximizes the profit of the entire supply chain (equal to the profit at full cooperation), on the other hand, minimizes the profit of the retailer (equal to the profit at price-only contract) so that the manufacturer maximizes its profit. The marketing cost-sharing results in the manufacture obtaining the second-highest profit because the manufacturer and the retailer cooperate to market the product, promoting the product's sale. Under a price-only contract, the manufacturer's profit is the lowest. It is the same as the prisoner's dilemma in the classic game case: each game participant 
chooses its optimal strategy while ignoring each other's cooperation and ends up with the lowest payment. This case illustrates the importance of cooperation between the participants in the game. Now we investigate the profits of the retailer. While the manufacturer obtains the highest profits under the two-part tariff system, the retailer obtains the same minimum profits as in the price-only contract in this case. Because the manufacturer takes full advantage of its first-mover advantage under the two-part tariff system, the retailer as the post-actor in the game can only accept the manufacturer's contract. Therefore, the manufacturer will not give the retailer a higher profit margin than under a price-only contract. Nevertheless, if they implement marketing cost-sharing, the profit level of the retailer is expected to increase under this limited form of cooperation.

\subsection{Consumer surplus, environmental impact and social welfare}

Next, we analyze the consumer surplus under different game approaches. Consumer surplus is the difference between the maximum price consumers willing to pay and the price they pay. It reflects the degree of improvement in the consumer's welfare situation obtained by consuming the good. The following formula calculates it:

$$
C S=\frac{1}{2}\left(\not p-p^{*}\right) D^{*}
$$

where $C S$ denotes the consumer surplus, $\quad \dot{p}$ is the the maximum price consumers are willing to pay, at this time $D^{*}=0$.

\section{Substituting the results for the four cases of full channel coordination, price-only contracts,} marketing cost-sharing, and the two-part fee system into Equation (14), one can get:

$$
\begin{aligned}
& C S_{d}^{*}=\frac{2 \alpha^{2} \beta^{2} \phi^{2}(1-c)^{2}}{\left[2 \alpha \beta(4 \phi-1)-\phi\left(\beta k_{1}^{2}+\alpha k_{2}^{2}\right)\right]^{2}} \\
& C S_{c s}^{*}=\frac{32 \alpha^{2} \beta^{2} \phi^{2}(1-c)^{2}}{\left[\alpha \beta(32 \phi-9)-4 \phi\left(\beta k_{1}^{2}+\alpha k_{2}^{2}\right)\right]^{2}} \\
& C S_{c}^{*}=C S_{t t}^{*}=\frac{2 \alpha^{2} \beta^{2} \phi^{2}(1-c)^{2}}{\left[\alpha \beta(4 \phi-1)-\phi\left(\beta k_{1}^{2}+\alpha k_{2}^{2}\right)\right]^{2}}
\end{aligned}
$$

Examining the consumer surplus in the four cases yields the following Proposition 4:

Proposition 4. Consumer surplus is the highest under full manufacturer-retailer cooperation and a two-part fee system. A marketing cost-sharing contract follows it. When implementing the 
price-only contract, consumers achieve the lowest surplus. I.e., $C S_{c}^{*}=C S_{t t}^{*}>C S_{c s}^{*}>C S_{d}^{*}$.

$$
\text { Please see the proof of Proposition } 4 \text { in Appendix } 8 .
$$

Under full manufacturer-retailer cooperation and a two-part fee system, as shown in Proposition 1, its price is the lowest, and demand is the highest, so consumer surplus is also the highest. On the other hand, the demand in the price-only contract case is the lowest, which leads to the lowest consumer surplus.

Next, we examine the beneficial effects of the increased greenness or reduced pollution emissions. Referring to Krass et al. (2013) and Hong et al. (2019), we assume that the environmental benefits can be measured in monetary terms and the coefficient of conversion of environmental benefits into money is $\varepsilon$. Furthermore, since the product's greenness is minimal under a price-only contract, the amount of currency that can be converted in this case is assumed to be 0 , i.e., $E I_{d}=0$. Taking the environmental benefits in this case as a benchmark, the environmental benefits in each of the other three cases can be expressed as

$$
E I_{d}=0
$$

$$
E I_{c s}=\varepsilon\left(e_{c s}^{*}-e_{d}^{*}\right) D_{c s}^{*}
$$

$$
E I_{t t}=\varepsilon\left(e_{t t}^{*}-e_{d}^{*}\right) D_{t t}^{*}=\varepsilon\left(e_{c}^{*}-e_{d}^{*}\right) D_{c}^{*}=E I_{c}
$$

Substituting the corresponding results obtained in Section 3 into them, get

$$
E I_{d}=0
$$

$$
E I_{c s}^{*}=\frac{8 \varepsilon \phi^{2} \alpha^{2} \beta^{3} k_{1}(1-c)^{2}}{\left[\alpha \beta(32 \phi-9)-4 \phi\left(\beta k_{1}^{2}+\alpha k_{2}^{2}\right)\right]^{2}\left[2 \alpha \beta(4 \phi-1)-\phi\left(\beta k_{1}^{2}+\alpha k_{2}^{2}\right)\right]}
$$

$$
E I_{t t}^{*}=E I_{c}^{*}=\frac{2 \varepsilon \phi^{2} \alpha^{2} \beta^{3} k_{1}(1-c)(4 \phi-1)}{\left[\alpha \beta(4 \phi-1)-\phi\left(\beta k_{1}^{2}+\alpha k_{2}^{2}\right)\right]^{2}\left[2 \alpha \beta(4 \phi-1)-\phi\left(\beta k_{1}^{2}+\alpha k_{2}^{2}\right)\right]}
$$

Investigating the environmental benefits under the several strategies, we obtain the following

\section{Proposition 5:}

Proposition 5. There are the following relationships about the environmental benefits under the four strategies: 


$$
E I_{d}^{*}<E I_{c s}^{*}<E I_{t t}^{*}=E I_{c}^{*}
$$

Please see the proof of Proposition 5 in Appendix 9.

Now, let us consider social welfare in four cases. In this paper, social welfare can be composed of three components: total supply chain profit, consumer surplus, and environmental benefits and is given by the following equation:

$$
S W=\pi+C S+E I
$$

Substituting the corresponding results obtained into Eq. (15), obtain social welfare in the four cases as:

$$
\begin{aligned}
& S W_{d}^{*}=\frac{\alpha \beta \phi(1-c)^{2}\left[\alpha \beta(14 \phi-3)-\phi\left(\beta k_{1}^{2}+\alpha k_{2}^{2}\right)\right]}{\left[2 \alpha \beta(4 \phi-1)-\phi\left(\beta k_{1}^{2}+\alpha k_{2}^{2}\right)\right]^{2}} \\
& S W_{c s}^{*}=\frac{4\left[2 \alpha \beta(4 \phi-1)-\phi\left(\beta k_{1}^{2}+\alpha k_{2}^{2}\right)\right] \alpha \beta \phi(1-c)^{2}\left[56 \alpha \beta \phi-15 \alpha \beta-4 \phi\left(\beta k_{1}^{2}+\alpha k_{2}^{2}\right)\right]+8 \varepsilon \phi^{2} \alpha^{2} \beta^{3} k_{1}(1-c)^{2}}{\left[\alpha \beta(32 \phi-9)-4 \phi\left(\beta k_{1}^{2}+\alpha k_{2}^{2}\right)\right]^{2}\left[2 \alpha \beta(4 \phi-1)-\phi\left(\beta k_{1}^{2}+\alpha k_{2}^{2}\right)\right]} \\
& S W_{t t}^{*}=S W_{c}^{*}=\frac{\alpha \beta \phi(1-c)^{2}\left\{5 \alpha^{2} \beta^{2}(4 \phi-1)^{2}-5 \alpha \beta \phi(4 \phi-1)\left(\beta k_{1}^{2}+\alpha k_{2}^{2}\right)+\left[\phi\left(\beta k_{1}^{2}+\alpha k_{2}^{2}\right)\right]^{2}\right\}}{\left[2 \alpha \beta(4 \phi-1)-\phi\left(\beta k_{1}^{2}+\alpha k_{2}^{2}\right)\right]^{2}\left[\alpha \beta(4 \phi-1)-\phi\left(\beta k_{1}^{2}+\alpha k_{2}^{2}\right)\right]} \\
& +\frac{2 \alpha^{2} \beta^{2} \phi^{2}(1-c)\left[2 \alpha \beta(4 \phi-1)(1-c)-\phi(1-c)\left(\beta k_{1}^{2}+\alpha k_{2}^{2}\right)+\varepsilon \beta k_{1}(4 \phi-1)\right]}{\left[2 \alpha \beta(4 \phi-1)-\phi\left(\beta k_{1}^{2}+\alpha k_{2}^{2}\right)\right]\left[\alpha \beta(4 \phi-1)-\phi\left(\beta k_{1}^{2}+\alpha k_{2}^{2}\right)\right]^{2}}
\end{aligned}
$$

Based on the above expression for social welfare, we give the following proposition:

Proposition 6. The social welfare following relationships exist between the four cases:

$$
S W_{d}^{*}<S W_{c s}^{*}<S W_{t t}^{*}=S W_{c}^{*}
$$

Please see the proof of Proposition 6 in Appendix 10.

\subsection{Numerical examples}

Up to this point, we have obtained the main conclusions through calculations and direct comparative analysis. Next, allow us to further demonstrate the conclusions with some numerical examples. For this purpose, we refer to relevant studies by Hong et al. (2019) to determine the range of values for each parameter and make initial assignments for each parameter. Then, carry out an initial numerical simulation. Finally, adjust the initial assignments of the parameters according to the simulation results until the simulation results of all variables are economically meaningful, and they are: $c=0.05, k_{1}=1.2, k_{2}=1.5, \alpha=2.6, \beta=2.2, \phi=1.1$. Apply 
543 Matlab software to simulate the main variables and obtain the following simulation analysis 544 graphs. Figures 5-7 show the same order of the optimal results under the different strategies 545 derived in subsection 4.2. Moreover, from it, one can derive the following new implications.

In terms of product quality and greenness, supply chain profitability and social welfare, marketing cost-sharing, two-part charging system, and complete cooperation have advantages over the price-only contract. Moreover, the latter two have apparent advantages. Looking at individual graphs, Fig. 5 shows that increasing green and conformance quality preferences improves product greenness and conformance quality under the four strategies. Furthermore, from the slope of the curve, the marginal effect of product greenness preference on greenness improvement is greater than the marginal effect on quality improvement; the marginal effect of conformance quality preference on quality improvement is greater than the marginal effect on greenness improvement.
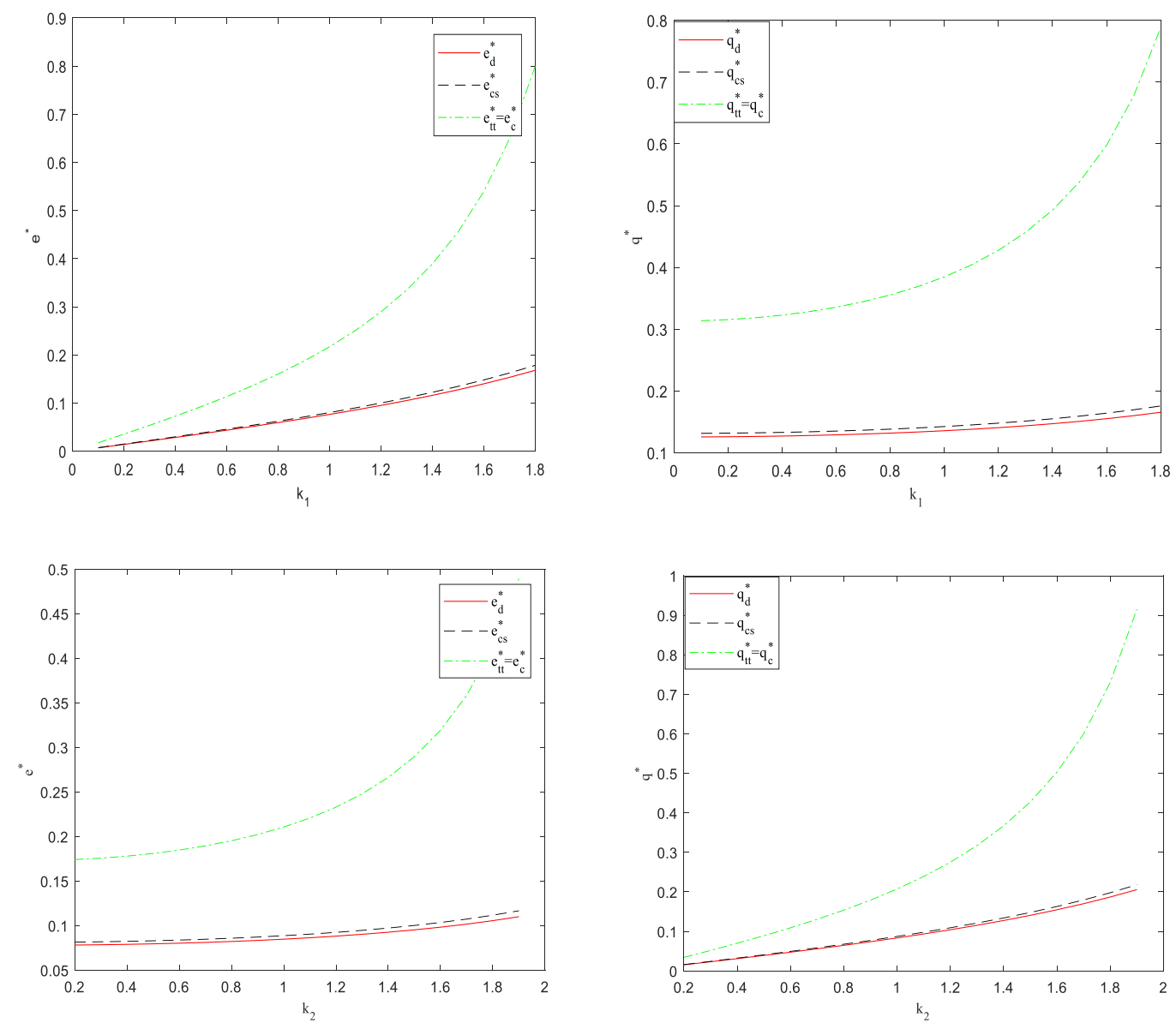

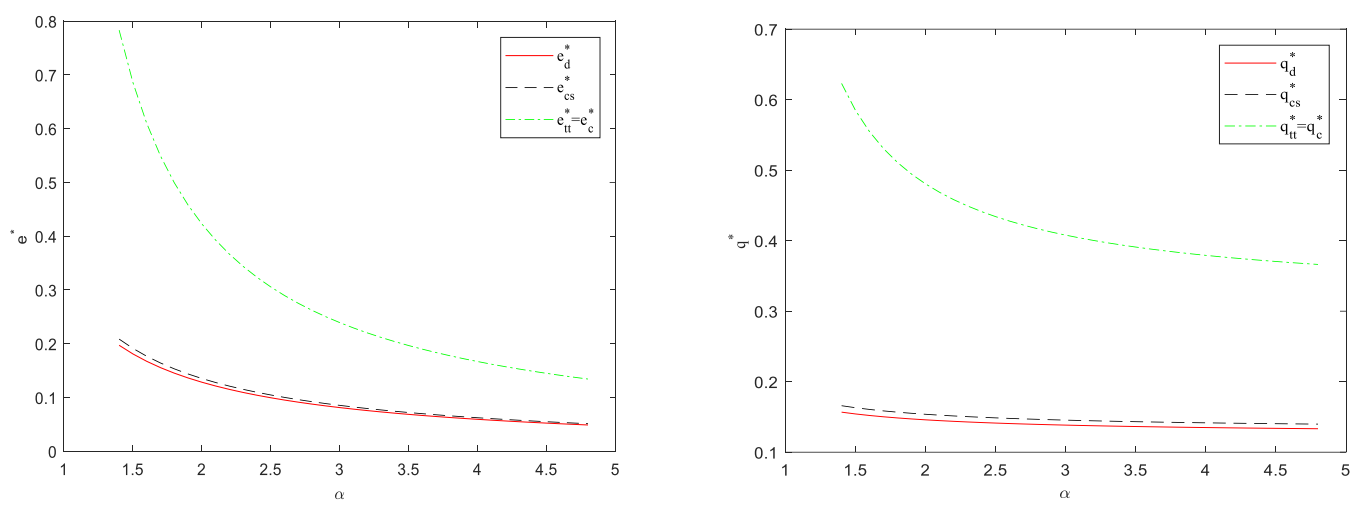

558
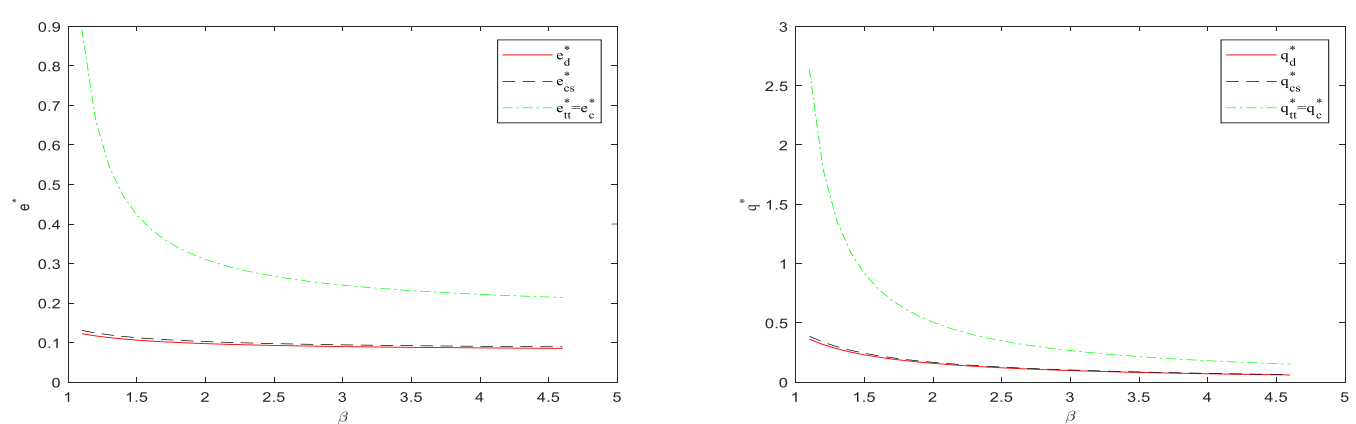

559
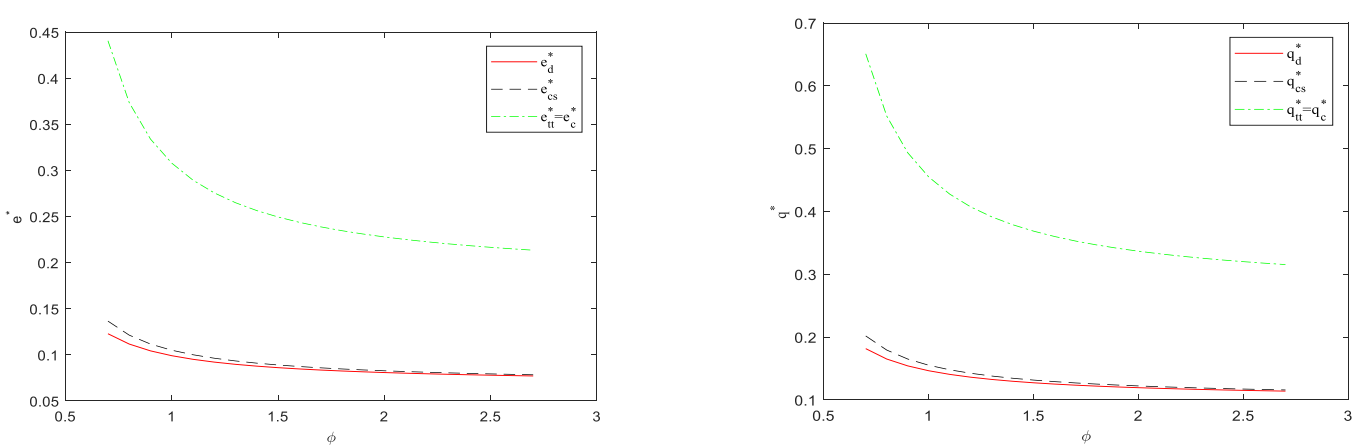

560

Fig.6 Changes in greenness and conformance quality with greenness and conformance quality improvement difficulty and marketing difficulty
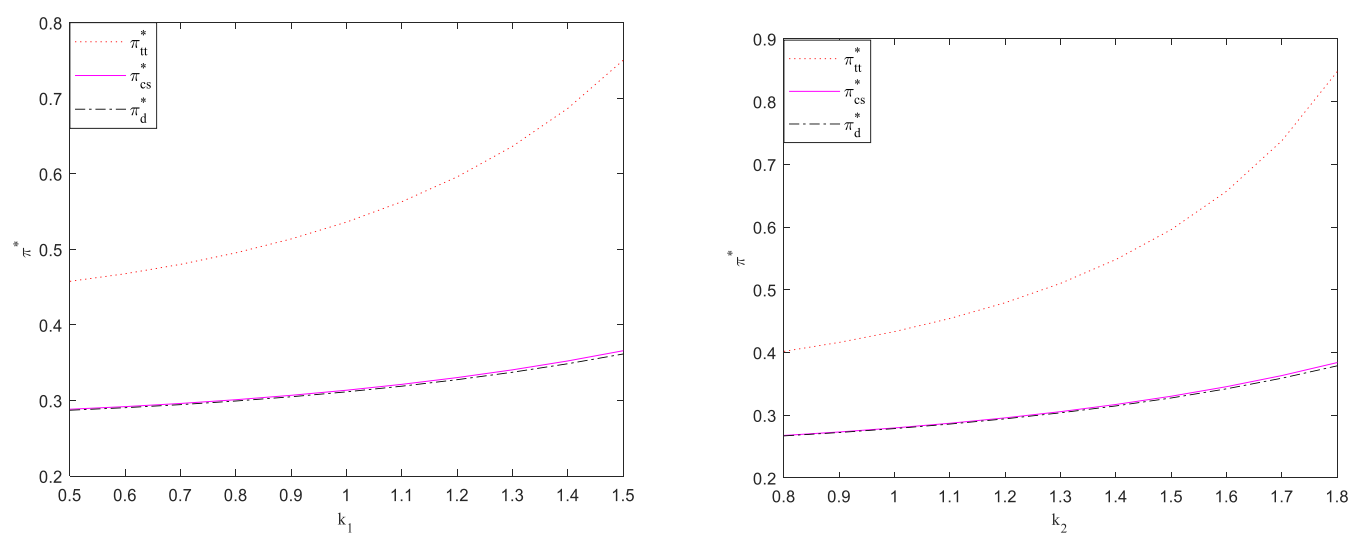

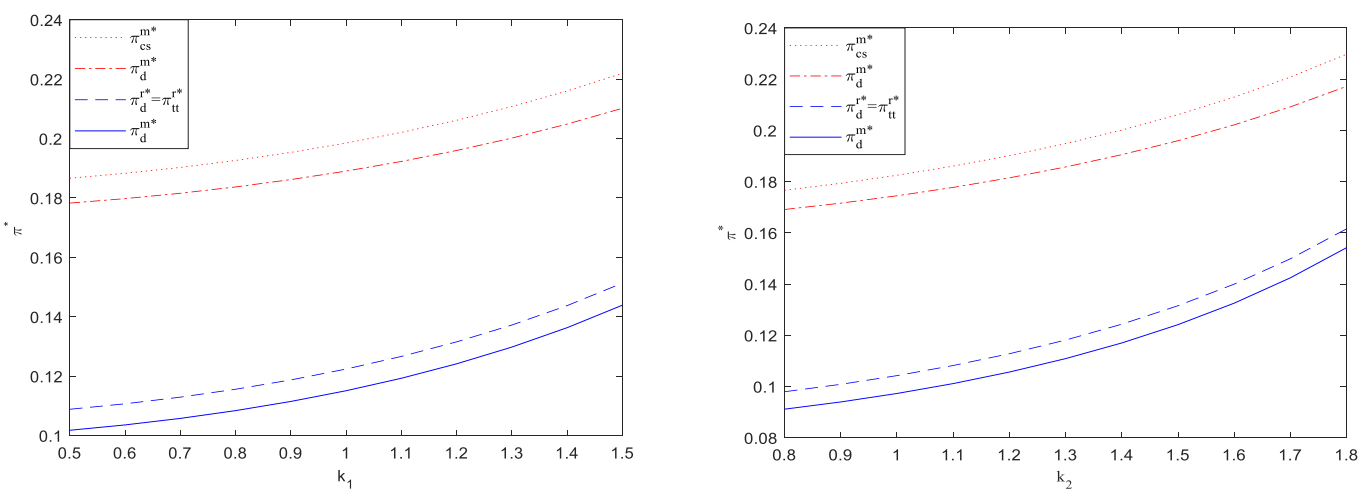

564

565

566

567 568 569 570

571

572

573

574

575

576

577

578
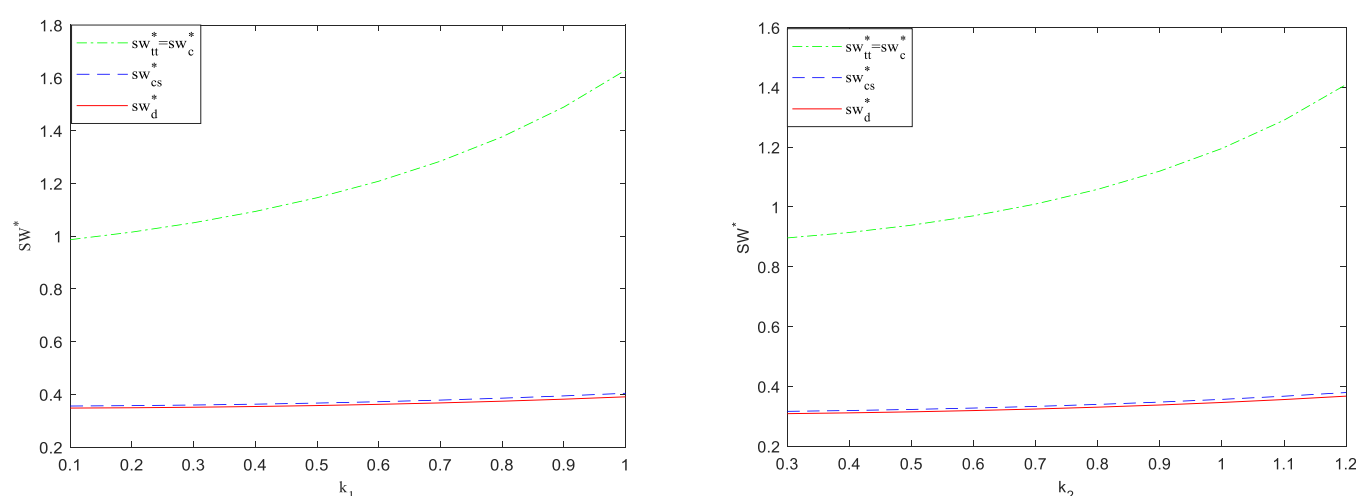

Fig.7 Profits and social welfare change with green and conformance quality preferences

Figure 6 depicts the effect of the three difficulty factors on the greenness and conformance quality of the product. In general, the difficulty coefficients of product greenness and conformance quality improvement and the difficulty coefficients of marketing effort increase on both product greenness and quality improvement with unfavorable marketing. In particular, the difference in the marginal effects of the same difficulty coefficients on greenness and quality improvement is not significant.

One can find from Fig.7 that overall profits and social welfare are significantly higher in the two cases of price discrimination and full cooperation than in the other two cases, and they are lowest in the case of price-only contracts. However, in profit-maximizing manufacturers and retailers, manufacturers prefer price discrimination contracts while retailers prefer the marketing cost-sharing case.

\section{Conclusion}

This study investigates the decision issue of the green product supply chain considering 
conformance quality of the product improvement and stakeholders' environmental responsibility.

Conformance quality preferences and environmental awareness of consumers are important market drivers for achieving a sustainable supply chain. The manufacturer determines the product design strategy in the business process, represented by the conformance quality and greenness. The retailers, in turn, determine the product marketing efforts to drive demand for their products. We analyzed four competitive and cooperative decisions between the manufacturer and retailer. Interesting management findings emerge from the comparison and discussion of the results for the four types of contracts:

(1) In all four cases, increased environmental awareness and conformance quality preferences promote improved conformance quality and greenness. Therefore, increasing consumers' environmental awareness is a necessary tool for ecological improvement.

(2) Although full channel coordination can lead to the highest product quality, product greenness, and total profit and social welfare, full cooperation between the manufacturer and retailer with different interests in the supply chain is difficult to achieve.

(3) The manufacturer-led two-part tariff contract results in outcomes consistent with full cooperation. Therefore, from the perspective of social managers, two-part tariff contracts are an excellent alternative to full channel coordination.

(4) Although two tariff contracts can lead to a socially optimal outcome, they may not ensure economic benefits for all partners. For example, the manufacturer can achieve the maximum profit under this contract, while the retailer receives a profit equal to the profit at the price-only contract, which is lower than the retailer's profit at the marketing cost-sharing.

When making decisions, these findings can provide valuable references for regulators and manufacturers and retailers in a supply chain.

This study has several limitations left to extend in future studies. In the model, we only consider the manufacturer's sharing of the retailer's marketing costs. Nevertheless, in reality, the buyer may also share the supplier's technology investment cost. For example, to improve the competitive advantage of the supply chain, Apple shares the cost of innovative technologies and technological development with its suppliers. In addition, from the government's perspective, designing optimal environmental policies to incentivize supply chains to reduce environmental externalities for sustainable development is another critical issue for future research. 
610 Yi Yongxi focuses on the conceptualization, methodology, writing original draft, Writing-review

611 \& editing. Yang Min focuses on the calculation, formal analysis. Fu Chunyan focuses on the

612 validation and writing-original draft. Li Yuqiong focuses on methodology, writing-original draft.

\section{$613 \quad$ Funding}

614 The study and collection, analysis, and interpretation of data were supported by the National

615 Natural Science Foundation of China (71974091), the Hunan Provincial Social Science Outcomes

616 Review Committee Major Projects (No. XSP20ZDA007),Natural Science Foundation of Hunan

617 Province (No. 2021JJ30584), Project of Hunan Social Science Achievement Evaluation

618 Committee (No. XSP22YBZ161).

619 Availability of data and materials

620 All data generated or analysed during this study are included in this published article

621 Compliance with ethical standards

622 Ethics approval

623 Not applicable

624 Consent to Participate

625 Not applicable

626 Consent to Publish

627 Not applicable

628 Competing interests

629 The authors declare that they have no competing interests

630

631

References

632

633

Atasu, A, Van Wassenhove, L.N , Sarvary, M., 2009. Efficient take-back legislation. Prod Oper Manag, 18(3):243-58 .

Baiman, S., Fischer, P.E., Rajan, M.V., 2000. Information, contracting, and quality costs. Manag. Sci, 46 (6), 776-789.

Basak, D., Wang L.F.S., 2016. Endogenous choice of price or quantity contract and the implications of two-part-tariff in a vertical structure. Econ Lett , 138, 53-56.

Chakraborty, T., Chauhan, S.S., Ouhimmou, M.,2019. Cost-sharing mechanism for product quality 
improvement in a supply chain under competition. Int J Prod Econ , 208, 566-587.

640 Chen, C., 2001. Design for the environment: a quality-based model for green product development. $641 \quad$ Manag Sci, 47(2):250-63.

642 Chen, J., Liang, L., Yao, D.Q. , \& Sun, S.,2017. Price and quality decisions in dual-channel supply chains. Eur J Oper Res, 259, 935-948 .

644

645

646

647

648

649

650

651

652

653

654

655

656

657

658

659

660

661

662

663

664

665

Chen, W.T., Hu, Z.H., 2018. Using evolutionary game theory to study governments and manufacturers' behavioral strategies under various carbon taxes and subsidies. J Clean Prod, $148,123-141$.

Durbin, D.A., Krisher, T., October 25, 2011. Consumer Reports Says Ford's Quality Slips. Associated Press. https://www.chron.com/business/article/ Consumer\%5c-Reports-saysFord-s-quality-slips-2235550.php/.

El, O.F. , \& Kogan, K., 2013. Dynamic conformance and design quality in a supply chain: an assessment of contracts’ coordinating power. Ann Oper Resa, 211, 137-166 .

Gaur, J , Amini, M., Rao, A., 2017. Closed-loop supply chain configuration for new and reconditioned products: an integrated optimization model. Omega, 66:212-23.

Gharaei, A., Karimi, M., Shekarabi, S.A.H., 2019. An integrated multi-product, multi-buyer supply chain under penalty, green, and quality control polices and a vendor managed inventory with consignment stock agreement: the outer approximation with equality relaxation and augmented penalty algorithm. Appl Math Model, 69, 223-254.

Ghosh, P.K., Manna, A.K., Dey, J.K., Kar, S.,2021. Supply chain coordination model for green product with different payment strategies: a game theoretic approach. J Clean Prod, 290(2), 125734.

Gouda, S.K, Jonnalagedda, S, Saranga, H., 2016. Design for the environment: impact of regulatory policies on product development. Eur J Oper Res, 248(2):558-70 .

Gray, John,V., Siemsen, Enno, Vasudeva, \& Gurneeta.,2015. Colocation still matters: conformance quality and the interdependence of $\mathrm{R} \& \mathrm{D}$ and manufacturing in the pharmaceutical industry. Manag Sci, 61(11), 2760-2781.

He, Y., Xu, Q., Xu, B., Wu, P., 2016. Supply chain coordination in quality improvement with reference effects. J. Oper Res Soc, 67 (9), 11581168.

Hendricks, K.B., Singhal, V.R., 2004. The effect of supply chain glitches on shareholder wealth. J 
Oper Manag, 21(5), 501-522.

Hong, Z, Chu, C., Zhang, L.L., Yu, Y., 2017. Optimizing an emission trading scheme for local governments: a Stackelberg game model and hybrid algorithm. Int J Prod Econ, 193:172-82 .

Hong, Z., Dai, W., Luh, H ., Yang, C., 2018. Optimal configuration of a green product supply chain with guaranteed service time and emission constraints. Eur J Oper Res, 266(2):663-77.

Hong, Z.F., Guo, X.L.,2019. Green product supply chain contracts considering environmental responsibilities. Omega, 83, 155-166.

Ji, X., Li, G., Wang, Z.,2017. Allocation of emission permits for China's power plants: A systemic Pareto optimal method. Appl Energy, 204, 607-19.

Krass, D., Nedorezov, T., Ovchinnikov, A.,2013. Environmental taxes and the choice of green technology. Prod Oper Manag, 22(5):1035-55.

Krishnan, M. S., Kriebel, C. H., Kekre, S., \& Mukhopadhyay, T. 2000. An empirical analysis of productivity and quality in software products. Manag Sci, 46(6), 745-759.

Lambertini, L.,2018. Coordinating research and development efforts for quality improvement along a supply chain. Eur J Oper Res, 270,599-605.

Lee, C.H., Rhee, B.D., \& Cheng, T.C.E., 2013. Quality uncertainty and quality compensation contract for supply chain coordination. Eur J Oper Res, 228 , 582-591.

Li, B., Wang, H., \& Zheng, W.,2021. Who will take on green product development in supply chains? manufacturer or retailer. J Clean Prod, 314,128000.

Li, G,. Wu, H.M., Sethi, S.P., Zhang, X.,2021. Contracting green product supply chains considering marketing efforts in the circular economy era. Int J Prod Econ, 234, 108041.

Liu, P.,2019. Pricing and coordination strategies of dual-channel green supply chain considering products green degree and channel environment sustainability. Int J Sustain Eng, 12 (6), 404-414.

Ma, P., Li, K.W., Wang, Z.J., 2017. Pricing decisions in closed-loop supply chains with marketing effort and fairness concerns. Int J Prod Res, 55 (22), 6710-6731.

Nandakumar, P., Datar, S. M., \& Akella, R.1993., Models for measuring and accounting for cost of conformance quality. Manag Sci, 39(1), 1-16.

Pakseresht, M., Shirazi, B., Mahdavi, I., Mahdavi-Amiri, N., 2020. Toward sustainable optimization with stackelberg game between green product family and downstream supply 
Reyniers, D.J., Tapiero, C.S.,1995. The delivery and control of quality in supplier- producer contracts. Manag Sci, 41, 1581-1589.

Thirumalai, S., Sinha, K.K., 2011. Product recalls in the medical device industry: an empirical exploration of the sources and financial consequences. Manag Sci, 57(2), 376-392.

Wang, J., Shin, H.,2015. The impact of contracts and competition on upstream innovation in a 705 supply chain. Prod. Oper Manag, 24 (1), 134-146.

Wang, Y., Yu, L., 2020. Can the current environmental tax rate promote green technology innovation? - evidence from china's resource-based industries. J Clean Prod, 278(2), 123443.

Yi, Y.X., Liu, S.Y., Fu, C.Y., Li, Y.Q., 2021b. Joint tax-subsidy for a manufacturing-recycling system under further extended producer responsibility. Sustain Prod Consump, 28, 610-623.

Yi, Y.X., Liu, S.Y., Fu, C.Y., Li, Y.Q.,2021a. A joint optimal emissions tax and solid waste tax for extended producer responsibility. J Clean Prod, 314, 128007.

\section{Appendix}

\section{Appendix 1}

\section{Proof of Theorem 1:}

we can obtain the unique optimal solutions $\left(p_{c}^{*}, t_{c}^{*}, e_{c}^{*}, q_{c}^{*}\right)$ with the conditions given by the 717

following first-order differential equations:

Sovle the Eq.(A1), we obtain the Theorem 1.

Finishing the proof.

\section{Proof of Corollary 1:}


$\left[\alpha \beta(4 \phi-1)-\varphi\left(\beta k_{1}^{2}+\alpha k_{2}^{2}\right)\right]^{2}>0$. Therefore, we can determine the positive and negative cases of the following derivatives as:

$$
\frac{\partial p_{c}^{*}}{\partial \alpha}=\frac{-2 \beta^{2} \phi^{2}(1-c) k_{1}^{2}}{\left[\alpha \beta(4 \phi-1)-\phi\left(\beta k_{1}^{2}+\alpha k_{2}^{2}\right)\right]^{2}}<0, \frac{\partial p_{c}^{*}}{\partial \beta}=\frac{-2 \alpha^{2} \phi^{2}(1-c) k_{2}^{2}}{\left[\alpha \beta(4 \phi-1)-\phi\left(\beta k_{1}^{2}+\alpha k_{2}^{2}\right)\right]^{2}}<0
$$$$
\frac{\partial p_{c}^{*}}{\partial \phi}=\frac{-2 \alpha^{2} \beta^{2}(1-c)}{\left[\alpha \beta(4 \phi-1)-\phi\left(\beta k_{1}^{2}+\alpha k_{2}^{2}\right)\right]^{2}}<0, \frac{\partial p_{c}^{*}}{\partial k_{1}}=\frac{4 \alpha \beta^{2} \phi^{2}(1-c) k_{1}}{\left[\alpha \beta(4 \phi-1)-\phi\left(\beta k_{1}^{2}+\alpha k_{2}^{2}\right)\right]^{2}}>0
$$$$
\frac{\partial p_{c}^{*}}{\partial k_{2}}=\frac{4 \alpha^{2} \beta \phi^{2}(1-c) k_{2}}{\left[\alpha \beta(4 \phi-1)-\varphi\left(\beta k_{1}^{2}+\alpha k_{2}^{2}\right)\right]^{2}}>0, \frac{\partial t_{c}^{*}}{\partial \alpha}=\frac{-\beta^{2} \phi(1-c) k_{1}^{2}}{\left[\alpha \beta(4 \phi-1)-\phi\left(\beta k_{1}^{2}+\alpha k_{2}^{2}\right)\right]^{2}}<0
$$

$\frac{\partial t_{c}^{*}}{\partial \beta}=\frac{-\alpha^{2} \phi(1-c) k_{2}^{2}}{\left[\alpha \beta(4 \phi-1)-\phi\left(\beta k_{1}^{2}+\alpha k_{2}^{2}\right)\right]^{2}}<0, \frac{\partial t_{c}^{*}}{\partial \phi}=\frac{-\alpha \beta(1-c)\left[4 \alpha \beta-\left(\beta k_{1}^{2}+\alpha k_{2}^{2}\right)\right]}{\left[\alpha \beta(4 \phi-1)-\phi\left(\beta k_{1}^{2}+\alpha k_{2}^{2}\right)\right]^{2}}<0$

$\frac{\partial t_{c}^{*}}{\partial k_{1}}=\frac{2 \alpha \beta^{2} \phi(1-c) k_{1}}{\left[\alpha \beta(4 \phi-1)-\phi\left(\beta k_{1}^{2}+\alpha k_{2}^{2}\right)\right]^{2}}>0, \frac{\partial t_{c}^{*}}{\partial k_{2}}=\frac{2 \alpha^{2} \beta \phi(1-c) k_{2}}{\left[\alpha \beta(4 \phi-1)-\phi\left(\beta k_{1}^{2}+\alpha k_{2}^{2}\right)\right]^{2}}>0$

$$
\frac{\partial e_{c}^{*}}{\partial \alpha}=\frac{\left.-\beta \phi k_{1}(1-c)\left[\beta(4 \phi-1)-\phi k_{2}^{2}\right)\right]}{\left[\alpha \beta(4 \phi-1)-\phi\left(\beta k_{1}^{2}+\alpha k_{2}^{2}\right)\right]^{2}}<0, \frac{\partial e_{c}^{*}}{\partial \beta}=\frac{-\alpha \phi^{2} k_{1} k_{2}^{2}(1-c)}{\left[\alpha \beta(4 \phi-1)-\phi\left(\beta k_{1}^{2}+\alpha k_{2}^{2}\right)\right]^{2}}<0
$$

$\frac{\partial e_{c}^{*}}{\partial \phi}=\frac{-\alpha \beta^{2} k_{1}(1-c)}{\left[\alpha \beta(4 \phi-1)-\phi\left(\beta k_{1}^{2}+\alpha k_{2}^{2}\right)\right]^{2}}<0, \frac{\partial e_{c}^{*}}{\partial k_{1}}=\frac{\beta \varphi(1-c)\left[\alpha \beta(4 \phi-1)+\varphi\left(\beta k_{1}^{2}-\alpha k_{2}^{2}\right)\right]}{\left[\alpha \beta(4 \phi-1)-\varphi\left(\beta k_{1}^{2}+\alpha k_{2}^{2}\right)\right]^{2}}>0$

$$
\frac{\partial e_{c}^{*}}{\partial k_{2}}=\frac{2 \alpha \beta \phi^{2} k_{1} k_{2}(1-c)}{\left[\alpha \beta(4 \phi-1)-\phi\left(\beta k_{1}^{2}+\alpha k_{2}^{2}\right)\right]^{2}}>0, \frac{\partial q_{c}^{*}}{\partial \alpha}=\frac{-\beta \phi^{2} k_{1}^{2} k_{2}(1-c)}{\left[\alpha \beta(4 \phi-1)-\phi\left(\beta k_{1}^{2}+\alpha k_{2}^{2}\right)\right]^{2}}<0
$$$$
\frac{\partial q_{c}^{*}}{\partial \beta}=\frac{\left.-\alpha \varphi(1-c) k_{2}\left[\alpha(4 \phi-1)-\phi k_{1}^{2}\right)\right]}{\left[\alpha \beta(4 \phi-1)-\phi\left(\beta k_{1}^{2}+\alpha k_{2}^{2}\right)\right]^{2}}<0, \frac{\partial q_{c}^{*}}{\partial \phi}=\frac{-\alpha^{2} \beta k_{2}(1-c)}{\left[\alpha \beta(4 \phi-1)-\phi\left(\beta k_{1}^{2}+\alpha k_{2}^{2}\right)\right]^{2}}<0
$$

$$
\frac{\partial q_{c}^{*}}{\partial k_{1}}=\frac{2 \alpha \beta \phi^{2} k_{1} k_{2}(1-c)}{\left[\alpha \beta(4 \phi-1)-\phi\left(\beta k_{1}^{2}+\alpha k_{2}^{2}\right)\right]^{2}}>0, \frac{\partial q_{c}^{*}}{\partial k_{2}}=\frac{\alpha \varphi(1-c)\left[\alpha \beta(4 \varphi-1)+\varphi\left(\alpha k_{2}^{2}-\beta k_{1}^{2}\right)\right]}{\left[\alpha \beta(4 \varphi-1)-\varphi\left(\beta k_{1}^{2}+\alpha k_{2}^{2}\right)\right]^{2}}>0
$$

Finishing the proof.

\section{Proof of Eq. (3):}

From Theorem 1, we get:

$$
p_{c}^{*}=c+\frac{2 \alpha \beta \varphi(1-c)}{\alpha \beta(4 \varphi-1)-\varphi\left(\beta k_{1}^{2}+\alpha k_{2}^{2}\right)}, t_{c}^{*}=\frac{\alpha \beta(1-c)}{\alpha \beta(4 \varphi-1)-\varphi\left(\beta k_{1}^{2}+\alpha k_{2}^{2}\right)}
$$

So, we can get: $t^{*}=\frac{p^{*}-c}{2 \phi}$. Finishing the proof.

\section{Appendix 2}




\section{Proof of Theorem 2:}

First, solve the follower's (retailer's) optimization problem according to equation (4): $\partial \pi_{d}^{r}\left(p_{d}, t_{d}\right) / \partial p_{d}=1-2 p_{d}+k_{1} e_{d}+k_{2} q_{d}+t_{d}+w_{d}=0 ; \partial \pi_{d}^{r}\left(p_{d}, t_{d}\right) / \partial t_{d}=p_{d}-w_{d}-2 \varphi t_{d}=0$.

Obtain its optimal solution and substitute it into the leader's (manufacturer's) optimization problem (7). Then solve its optimization problem jointly $\partial \pi_{d}^{m}\left(w_{d}, e_{d}, q_{d}\right) / \partial w_{d}=0 ; \partial \pi_{d}^{m}\left(w_{d}, e_{d}, q_{d}\right) / \partial e_{d}=0$; $\partial \pi_{d}^{m}\left(w_{d}, e_{d}, q_{d}\right) / \partial q_{d}=0$. Finally, we collate the computational results to obtain Theorem 2. Finishing the proof.

\section{Proof of Corollary 2:}

From Theorem 2, we get the Corollary 2. Since the proof of Statement 2 is similar to the proof of theorem 1 , its detailed proof is omitted here.

\section{Appendix 3}

\section{Proof of Theorem 3:}

The manufacturer's optimization problem (equation 9) shows that the manufacturer can increase the fixed charge to the retailer until the retailer's net revenue is exactly equal to its net revenue at the time of the price-only contract. That is, the constraint faced by the manufacturer is $\left(p_{t t}^{*}-w_{t t}\right)\left(1-p_{t t}^{*}+k_{1} e_{t t}+k_{2} q_{t t}+t_{t t}^{*}\right)-\phi t_{t t}^{* 2}-T=\pi_{d}^{r^{*}}$. Then, the optimal solutions can be obtained as follows: $e_{t t}^{*}=\frac{\phi \beta k_{1}(1-c)}{\alpha \beta(4 \phi-1)-\phi\left(\beta k_{1}^{2}+\alpha k_{2}^{2}\right)} ; q_{t t}^{*}=\frac{\phi \alpha k_{2}(1-c)}{\alpha \beta(4 \phi-1)-\phi\left(\beta k_{1}^{2}+\alpha k_{2}^{2}\right)}$

$p_{t t}^{*}=c+\frac{2 \alpha \beta \phi(1-c)}{\alpha \beta(4 \phi-1)-\phi\left(\beta k_{1}^{2}+\alpha k_{2}^{2}\right)} ; t_{t t}^{*}=\frac{\alpha \beta(1-c)}{\alpha \beta(4 \phi-1)-\phi\left(\beta k_{1}^{2}+\alpha k_{2}^{2}\right)} ; w_{t t}^{*}=c$ $T=\frac{\phi(\alpha \beta(1-c))^{2}(4 \phi-1)}{\left[\alpha \beta(4 \phi-1)-\phi\left(\beta k_{1}^{2}+\alpha k_{2}^{2}\right)\right]^{2}}-\frac{\phi(\alpha \beta(1-c))^{2}(4 \phi-1)}{\left[2 \alpha \beta(4 \phi-1)-\phi\left(\beta k_{1}^{2}+\alpha k_{2}^{2}\right)\right]^{2}}$. Finishing the proof.

\section{Appendix 4}

\section{Proof of Theorem 4:}

First, solve the retailer's optimization problem according to equation (12):

$\partial \pi_{c s}^{r}\left(p_{c s}, t_{c s}\right) / \partial p_{c s}=1-2 p_{c s}+k_{1} e_{c s}+k_{2} q_{c s}+t_{c s}+w_{c s}=0 ; \partial \pi_{c s}^{r}\left(p_{c s}, t_{c s}\right) / \partial t_{c s}=p_{c s}-w_{c s}-2(1-\eta) \varphi t_{c s}=0$

Obtain its optimal solution and substitute it into the leader's (manufacturer's) optimization problem (13). Then solve its optimization problem jointly 
Finally, we collate the computational results to obtain Theorem 4. Finishing the proof.

769

770

\section{Appendix 5}

\section{Proof of Proposition1:}

The numerators of $e_{d}^{*}, e_{c s}^{*}, e_{t t}^{*}$, are the same, but the denominators are different. So we compare their denominators. $e_{d}^{*}$ 's denominator minus $e_{c s}^{*}$ 's denominator equals $0.25 \alpha \beta>0$. Therefore, $e_{d}^{*}<e_{c s}^{*}$. While $e_{c s}^{*}$ 's denominator minus $e_{t t}^{*}$ 's denominator equals $\alpha \beta(4 \phi-1.25)>0$. So, $e_{c s}^{*}<e_{t t}^{*}$. Meanwhile, we have obtained $e_{t t}^{*}=e_{c}^{*}$. In conclusion $e_{d}^{*}<e_{c s}^{*}<e_{t t}^{*}=e_{c}^{*}$

Similarly, we obtain the remaining inequalities by subtracting the denominator, subtracting the numerator, or subtracting both the numerator and the denominator of the expression of the optimal result. Finishing the proof.

\section{Proof of Proposition2:}

$$
\begin{aligned}
& (1-\eta) \phi\left(t_{c s}^{*}\right)^{2}-\phi\left(t_{d}^{*}\right)^{2}=\frac{2}{3} \phi\left[\frac{6 \alpha \beta(1-c)}{\alpha \beta(32 \phi-9)-4 \phi\left(\beta k_{1}^{2}+\alpha k_{2}^{2}\right)}\right]^{2}-\phi\left[\frac{\alpha \beta(1-c)}{2 \alpha \beta(4 \phi-1)-\phi\left(\beta k_{1}^{2}+\alpha k_{2}^{2}\right)}\right]^{2} \\
& =\phi \alpha^{2} \beta^{2}(1-c)^{2}\left[\frac{1.5}{\left[\alpha \beta(8 \phi-2.25)-\phi\left(\beta k_{1}^{2}+\alpha k_{2}^{2}\right)\right]^{2}}-\frac{1}{\left[\alpha \beta(8 \phi-2)-\phi\left(\beta k_{1}^{2}+\alpha k_{2}^{2}\right)\right]^{2}}\right]
\end{aligned}
$$

Because $1.5>1$, and $\left[\alpha \beta(8 \phi-2.25)-\phi\left(\beta k_{1}^{2}+\alpha k_{2}^{2}\right)\right]^{2}<\left[\alpha \beta(8 \phi-2)-\phi\left(\beta k_{1}^{2}+\alpha k_{2}^{2}\right)\right]^{2}$. Get:

$$
(1-\eta) \phi\left(t_{c s}^{*}\right)^{2}>\phi\left(t_{d}^{*}\right)^{2} \text {.Finishing the proof. }
$$

\section{Appendix 7}

\section{Proof of Proposition 3:}

$$
\text { Proof } \pi_{d}^{m^{*}}<\pi_{c s}^{m^{*}}<\pi_{t t}^{m^{*}}
$$

1) Rectifying $\pi_{t t}^{m^{*}}-\pi_{c s}^{m^{*}}$, we get

$\pi_{t t}^{m^{*}}-\pi_{c s}^{m^{*}}=\phi(\alpha \beta(1-c))^{2}\left\{\frac{(4 \phi-1.25)[2 \alpha \beta(4 \phi-1)-\phi x]^{2}-(4 \phi-1)[\alpha \beta(4 \phi-1)-\phi x][\alpha \beta(8 \phi-2.25)-\phi x]}{[\alpha \beta(4 \phi-1)-\phi x][\alpha \beta(8 \phi-2.25)-\phi x][2 \alpha \beta(4 \phi-1)-\phi x]^{2}}\right\}$ 
For ease of presentation, where we let $\left(\beta k_{1}^{2}+\alpha k_{2}^{2}\right)=x>0$. Same below.

$$
\begin{aligned}
& (4 \phi-1.25)\left[4(\alpha \beta(4 \phi-1))^{2}+\phi^{2} x^{2}-4 \alpha \beta \phi(4 \phi-1) x\right]-(4 \phi-1)\left[(\alpha \beta)^{2}(4 \phi-1)(8 \phi-2.25)-\alpha \beta \phi x(12 \phi-3.25)+\phi^{2} x^{2}\right] \\
& =(\alpha \beta)^{2}(4 \phi-1)(2 \phi-1)(8 \phi-1)-0.25 \phi^{2} x^{2}+\alpha \beta(4 \phi-1)(4 \phi-1.5-0.25)[\alpha \beta(4 \phi-1)-\phi x] \\
& =(\alpha \beta)^{2}\left((4 \phi-1)(2 \phi-1)(8 \phi-1)-0.25(4 \phi-1)^{2}\right)+0.25 \phi\left(\beta k_{1}^{2}+\alpha k_{2}^{2}\right)\left(\alpha \beta(4 \phi-1)-\phi\left(\beta k_{1}^{2}+\alpha k_{2}^{2}\right)\right) \\
& \quad+\alpha \beta(4 \phi-1)(4 \phi-1.5)\left[\alpha \beta(4 \phi-1)-\phi\left(\beta k_{1}^{2}+\alpha k_{2}^{2}\right)\right] \\
& =(\alpha \beta)^{2}\left((4 \phi-1)(2 \phi-1)(8 \phi-1)-0.25(4 \phi-1)^{2}\right)+0.25 \phi x(\alpha \beta(4 \phi-1)-\phi x) \\
& +\alpha \beta(4 \phi-1)(4 \phi-1.5)[\alpha \beta(4 \phi-1)-\phi x] \\
& \quad(\alpha \beta)^{2}\left[(4 \phi-1.5)^{2}+(4 \phi-1.5)(15 \phi-1.375)+0.0625\right]+0.25 \phi x(\alpha \beta(4 \phi-1)-\phi x) \\
& \quad+\alpha \beta(4 \phi-1)(4 \phi-1.5)[\alpha \beta(4 \phi-1)-\phi x]
\end{aligned}
$$

800

801

Because $\pi_{c s}^{r *}>0$, There will be: $(4 \phi-1.5)>0, \phi>0.375$. therefore, the above

equation is greater than zero. I.e., $\pi_{t t}^{m^{*}}-\pi_{c s}^{m^{*}}>0$.

$$
\text { 2) } \pi_{c s}^{m^{*}}-\pi_{d}^{m^{*}}=\frac{\alpha \beta \phi(1-c)^{2}}{[2 \alpha \beta(4 \phi-1.125)-\phi x]}-\frac{\alpha \beta \phi(1-c)^{2}}{[2 \alpha \beta(4 \phi-1)-\phi x]}
$$

806

$$
\text { Because }[2 \alpha \beta(4 \phi-1.125)-\phi x]<[2 \alpha \beta(4 \phi-1)-\phi x] \text {, }
$$

Therefore, $\pi_{c s}^{m^{*}}-\pi_{d}^{m^{*}}>0$

To sum up, we get $\pi_{d}^{m^{*}}<\pi_{c s}^{m^{*}}<\pi_{t t}^{m^{*}}$.

807

$$
\text { Proof } \pi_{d}^{r^{*}}=\pi_{t t}^{r^{*}}<\pi_{c s}^{r^{*}}
$$

$$
\text { Compare } \pi_{c s}^{r^{*}} \text { and } \pi_{t t}^{r^{*}}:
$$

$$
\pi_{c s}^{r^{*}}-\pi_{t t}^{r^{*}}=\phi \alpha^{2} \beta^{2}(c-1)^{2}\left\{\frac{(4 \phi-1.5)[2 \alpha \beta(4 \phi-1)-\phi x]^{2}-(4 \phi-1)[\alpha \beta(8 \phi-2.25)-\phi x]^{2}}{[\alpha \beta(8 \phi-2.25)-\phi x]^{2}[2 \alpha \beta(4 \phi-1)-\phi x]^{2}}\right\}
$$




$$
(\alpha \beta)^{2}(4 \phi-1)^{2}(8 \phi-2.125)-\alpha \beta \phi(4 \phi-1)^{2} x
$$

$$
-2(\alpha \beta)^{2}(4 \phi-1)^{2}+2 \alpha \beta \phi(4 \phi-1) x-0.5 \alpha \beta \phi(4 \phi-1.5) x+0.5 \alpha \beta \phi(4 \phi-1.5) x-0.5 \phi^{2} x^{2}
$$

$=128(\alpha \beta)^{2} \phi^{3}-130(\alpha \beta)^{2} \phi^{2}+25(\alpha \beta)^{2} \phi+41(\alpha \beta)^{2} \phi-4.125(\alpha \beta)^{2}-(\alpha \beta)^{2}\left(16 \phi^{2}-14 \phi+2.25\right)(4 \phi-1.5)$

$+\alpha \beta\left(16 \phi^{2}-14 \phi+2.25\right)[\alpha \beta(4 \phi-1.5)-\phi x]+0.5 \phi x[\alpha \beta(4 \phi-1.5)-\phi x]$

$$
\begin{aligned}
& =0.46875(\alpha \beta)^{2}+(\alpha \beta)^{2}\left[\phi(8 \phi-2.625)^{2}+31.859375 \phi-1.28125\right]+0.8125 \alpha \beta x, \\
& +\alpha \beta\left[(4 \phi-1.75)^{2}+0.25\right][\alpha \beta(4 \phi-1)-\phi x]+0.5 \phi x[\alpha \beta(4 \phi-1)-\phi x]>0
\end{aligned},
$$

$$
\pi_{d}^{r^{*}}=\pi_{t t}^{r^{*}}<\pi_{c s}^{r^{*}}
$$

$$
\text { Proof } \pi_{d}^{*}<\pi_{c s}^{*}<\pi_{t t}^{*}=\pi_{c}^{*}
$$

$$
\pi_{t t}^{*}-\pi_{c s}^{*}=\alpha \beta \phi(1-c)^{2}\left\{\frac{[\alpha \beta(8 \phi-2.25)-\phi x]^{2}-[12 \phi \alpha \beta-3.75 \alpha \beta-\phi x][\alpha \beta(4 \phi-1)-\phi x]}{[\alpha \beta(4 \phi-1)-\phi x][\alpha \beta(8 \phi-2.25)-\phi x]^{2}}\right\}
$$

The numerator in (A4) curly braces is equal to:

$$
\alpha^{2} \beta^{2}(8 \phi-2.25)^{2}-2 \alpha \beta \phi(8 \phi-2.25) x+\phi^{2} x^{2}-\left\{12 \phi \alpha^{2} \beta^{2}(4 \phi-1)-12 \phi^{2} \alpha \beta x\right.
$$

$\left.-\alpha \beta \phi(4 \phi-1) x+\phi^{2} x^{2}-3.75 \alpha^{2} \beta^{2}(4 \phi-1)+3.75 \alpha \beta \phi x\right\}$

$=\alpha^{2} \beta^{2}(4 \phi-1.25)^{2}+0.25 \alpha \beta\left[\alpha \beta(4 \phi-1)-\phi\left(\beta k_{1}^{2}+\alpha k_{2}^{2}\right)\right]>0$

Therefore $\pi_{t t}^{*}>\pi_{c s}^{*}$.

We have known that $\pi_{t t}^{*}=\pi_{c}^{*}$. And $\pi_{c s}^{* r}>\pi_{d}^{* r} \pi_{c s}^{* m}>\pi_{d}^{* m}$, so $\pi_{c s}^{*}>\pi_{d}^{*}$.

\section{Appendix 8}

Proof of Proposition 4:

830

Proof is similar to Appendix 5. Therefore, we omit the proof of the Appendix 8.

\section{Appendix 9}




$$
E I_{t t}^{*}-E I_{c s}^{*}=\frac{2 \varepsilon \phi^{2} \alpha^{2} \beta^{3} k_{1}(1-c)(4 \phi-1)}{[2 \alpha \beta(4 \phi-1)-\phi x]}\left\{\frac{[\alpha \beta(16 \phi-4.5)-2 \phi x]^{2}-[\alpha \beta(4 \phi-1)-\phi x]^{2}}{[\alpha \beta(4 \phi-1)-\phi x]^{2}[\alpha \beta(16 \phi-4.5)-2 \phi x]^{2}}\right\}
$$

\section{Appendix 10}

Proof of Proposition 6: $S W_{d}^{*}<S W_{c s}^{*}<S W_{t t}^{*}=S W_{c}^{*}$ 
858

859

860

861 